This report was prepared as an account of work sponsored by an agency of the United States Government. Neither the United States Government nor any agency thereof, nor any of their employees, makes any warranty, express or implied, or assumes any legal liability or responsibility for the accuracy, completeness, or usefulness of any information, apparatus, product, or process disclosed, or represents that its use would not infringe privately owned rights. Reference herein to any specific commercial product, process, or service by trade name, trademark, manufacturer, or otherwise does not necessarily constitute or imply its endorsement, recommendation, or favoring by the United States Government or any agency thereof. The views and opinions of authors expressed herein do not necessarily state or reflect those of the United States Grvernment or any agency thereof.

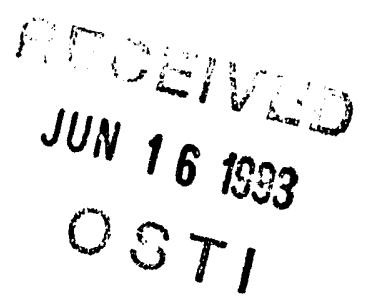

\title{
EVALUATION OF THE INTERFACIAL MECHANICAL PROPERTIES IN FIBER-REINFORCED CERAMIC
COMPOSITES
}

\author{
M. K. Ferber, A. A. Wereszczak, L. Riester, and R. A. Lowden \\ Oak Ridge National Laboratory, Oak Ridge, TN 37831 \\ K. K. Chawla \\ New Mexico Tech., Socorro, NM 87801
}

\section{ABSTRACT}

The present study examined the application of a micro-indentation technique to the measurement of interfacial mechanical properties in fiber reinforced ceramic composites. Specific fiber/matrix systems included SiC/glass, $\mathrm{SiC} / \mathrm{macro}$-defect-free (MDF) cement, SiC/SiC, and was also investigated. These properties, which included the debond
strength, ir erfacial shear stress, and evaluated by meal shear stress, and residual axial fiber stress, were load-unload cycles. Estimates of these three stress garves generated during obtained by matching the experimental force stress values were data predicted from an existing model.

In general the $\mathrm{SiC} / g$ lass composites exhibited the lowest values of the interfacial shear and debond stresses. The sliding characteristics of the SiC/MDF cement and $\mathrm{SiC} / \mathrm{SiC}$ composites were strongly influenced by the residual axial stress and the nature of the fiber coating. In the case of the mullite/glass composite, the high values of the interfacial thereby increasing the uncertainty in the measurement sensitivity, properties.

* Research sponsored by the Department of Energy, Assistant Secretary for Conservation and Renewable Energy, Office of Transportation Technologies, as part of the High Temperature Materials Laboratory User Program, under contract DE-AC05-84OR21400 with Martin Marietta Energy Systems, Inc. 


\section{INTRODUCTION}

Future energy-efficient heat engines will utilize high-performance structural materials in selected elevated-temperature areas. While monolithic ceramics such as silicon carbide and silicon nitride have been cited as excellent candidate materials for these applications, their inherent brittleness has limited their utilization as structural components. One promising solution involves the use of continuous fiber ceramic composites (CFCCs). Because these composite materials are significantly tougher than their monolithic counterparts, high-temperature structural components which are fabricated from ceramic composites should be more damage tolerant.

The optimization of the mechanical performance of CFCCs for specific high-temperature applications requires knowledge of both the constituent and interfacial (micro-mechanical) properties. For example, high toughness is generally associated with concurrently active fiber bridging and fiber pull-out processes. To maximize the bridging contribution, debonding must occur before fiber fracture as a macroscopic crack approaches a fiber. This condition is maintained as long as the ratio of the fiber strength to the interfacial shear strength, $\mathrm{S}_{\mathrm{f}} / \tau_{\mathrm{S}}$, exceeds a critical value which is determined by the fiber volume fraction, the shear transfer length, and fiber/matrix elastic properties. ${ }^{1} \mathrm{~A}$ second condition required to maximize the toughness is that once the fiber has debonded, the matrix must remain in contact with the fiber. This will occur as long as the ratio of the residual interfacial clamping (radial) stress to the interfacial shear strength, $\sigma^{R_{i r}} / \tau_{s}$, exceeds a critical value which again is a function of the fiber volume fraction and fiber/matrix elastic properties. 1

The increment of toughening, $\Delta \mathrm{J}$, arising from fiber pull-out and fiber bridging will also be dependent upon the interfacial properties. Analyses have shown that $\Delta J$ (pull-out) $\propto\left(\mu \sigma^{\mathrm{R}} \mathrm{mz}\right)$ and $\Delta J$ (bridging) $\propto$ $1 /\left(\mu^{2} \sigma^{R} \mathrm{mz}\right)$, where $\mu$ is the coefficient of friction and $\sigma_{\mathrm{mz}}^{\mathrm{R}}$ is the residual axial stress in the matrix.2 This latter parameter can be related to the residual axial stress in the fiber, $\sigma^{R_{f z}}$. Maximum toughening is expected when an optimum comprimise between these parameters is achieved.

The first matrix cracking stress, $\sigma_{\mathrm{mu}}$, is another macroscopic property which is strongly dependent upon interfacial characteristics. For the case of a simple unidirectional fiber-reinforced composite, $\sigma_{\mathrm{mu}}$ is given by,

where

$$
\sigma_{m u} / E_{c}=\left\{\left[12 \tau_{i} \gamma_{m} V_{f}^{2} E_{f}\right] /\left[r V_{m} E_{c} E_{m}^{2}\right]\right\}^{1 / 3}
$$

$$
E_{c}=\left(V_{f} E_{f}+V_{m} E_{m}\right) \text {, }
$$

$\tau_{i}$ is the interfacial sliding shear stress, $\gamma_{m}$ is the fracture energy of the matrix, $E$ is the elastic modulus, $V$ is the volume fraction, and $r$ is the fiber radius. 3 The subscripts $c, m$, and $f$ refer to the composite, matrix, and 
fiber, respectively. Equation 1 is valid when the residual axial stresses are zero. For a nonzero value of $\sigma^{\mathrm{R}} \mathrm{mz}, \sigma_{\mathrm{mu}}$ is given by ${ }^{3}$

$$
\sigma_{m u} / E_{c}+\sigma_{m z}^{R} / E_{m}=\left\{\left[12 \tau_{i} \gamma_{m} V_{f}^{2} E_{f}\right] /\left[r V_{m} E_{c} E_{m}^{2}\right]\right\}^{1 / 3}
$$

Because of the importance of interfacial properties in controlling the mechanical response of CFCCs, considerable effort has been directed towards the development of experimental techniques and mathematical expressions required to estimate these properties from fiber sliding experiments. One commonly applied technique involves displacing individual fibers with a micro-indenter or mechanical properties microprobe (MPM) equipped with both load and displacement sensors. 4,5

Figure 1 provides a schematic representation of the stressdisplacement characteristics of a fiber loaded with the MPM. Because the sliding length in such a test is generally much smaller than the overall specimen thickness, the fiber is pushed into the matrix but not through it (i.e., a fiber push-in test). The debond stress, $\sigma_{\mathrm{d}}$, is the stress at which sliding initiates and is a function of the interfacial shear strength, $\tau_{\mathbf{s}}$. The shape of the loading curve depends upon $\mu, \sigma^{R}{ }_{i r}, \sigma^{R_{f z}}{ }^{\star}$, and the elastic properties of both the matrix anc fiber. During unloading, the extent of fiber recovery as characterized by the ratio, $u_{0} / u_{\max }$, depends strongly upon the values of $\sigma R_{f z}$ and the Poisson's ratio of the fiber, $v_{f}$. When $\sigma R_{f z}$ and $v_{f}$ are zero, $u_{o} / u_{\max }$ will be 0.5 (Ref. 5). However, as either $\sigma R_{f z}$ or $v_{f}$ become more positive, $u_{0} / u_{\max }$ decreases accordingly.

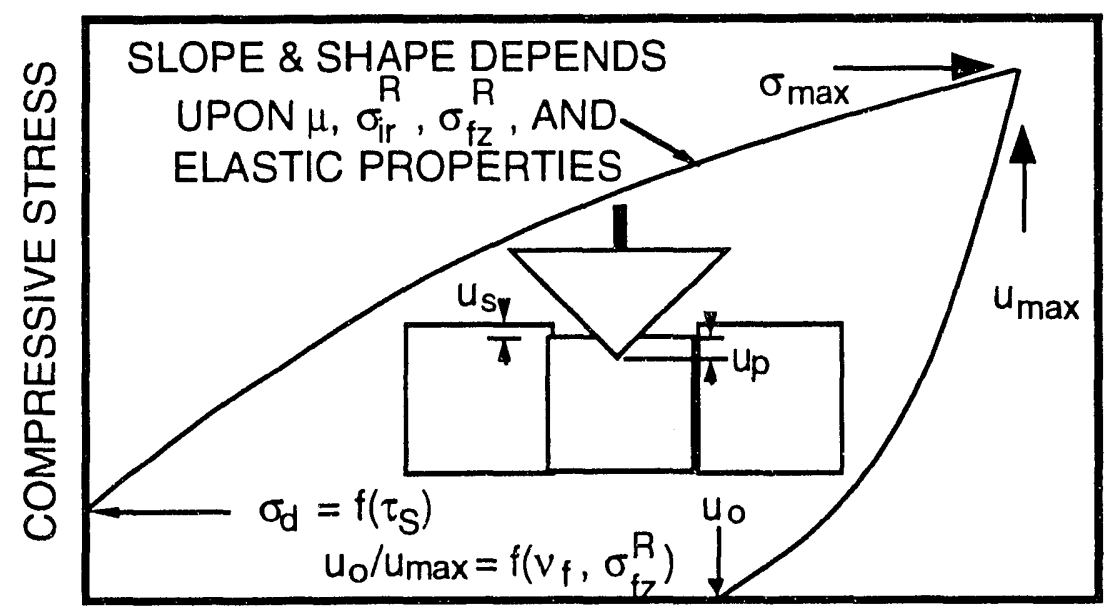

FIBER DISPLACEMENT, $u_{S}$

Figure 1. Schematic Representation of the Stress-Displacement Characteristics Obtained from Indentation Push-In Test.

* Unless otherwise stated, positive values of $\sigma^{R_{i r}}, \sigma^{R_{f z}}$, and $\sigma_{d}$ denote compressive stresses. 
Numerous models have been developed to describe the stressdisplacement curves like the one in Fig. 1 in terms of the interfacial properties. ${ }^{4-10}$ For example, Marshall and Oliver ${ }^{5}$ specifically addressed the effects of the residual axial stress, $\sigma^{R_{f z}}$, upon the shape stressdisplacement $\left(\sigma-u_{s}\right)$ curves generated during loading/unloading. While their model also accounted for fiber debonding, it neglected the effects of the Poisson's expansion of the fiber during loading. These Poisson's ratio effects were considered in an early model by $\mathrm{Hsueh}^{6}$ by including a term for the interfacial clamping stress induced from the Poisson's expansion of the fiber, $\sigma_{i r}$ in the expression,

$$
\tau_{i}=\mu\left(\sigma^{R_{i r}}+\sigma_{i r}\right)
$$

Variations of $\sigma_{i r}$ along the sliding length result in similar variations in $\tau_{i}$. Two limitations of his model were that it (1) required an iterative numerical solution for the fiber sliding length and (2) did not account for the effects of either residual axial or debond stresses upon the $\sigma-u_{s}$ behavior. Both limitations have been addressed in a more recent model which simplifies the calculation of the interfacial properties by averaging the Poisson's ratio effects over the sliding length. 7

The present study summarizes results of recent fiber sliding studies involving SiC/glass, SiC/macro-defect-free (MDF) cement, $\mathrm{SiC} / \mathrm{SiC}$, and mullite/glass composites. The motivation of these studies was to examine the application of both the micro-indentation push-in technique and the associated mathematical models to the measurement of interfacial mechanical properties. The effect of fiber coatings upon the interfacial properties was also investigated. Estimates of debond stress, interfacial sliding shear stress, and residual axial fiber stress were obtained by first measuring the force-displacement curves and then matching these curves with data predicted from existing models.

\section{EXPERIMENTAL PROCEDURE}

Table 1 summarizes the composite systems examined in the embedded in an $31.8 \mathrm{~mm}$ (1.25") diameter plastic mount such that the fibers were perpendicular to the mount surface. This surface was subsequently ground and polished to a $0.25 \mu \mathrm{m}$ finish using standard ceramographic techniques.

For each of the composite systems listed in Table 1, a minimum of 5 fibers was loaded using a commercial MPM." The MPM used in the present study is capable of accurately applying $\mathrm{mN}$ loads via a Berkovich pyramidal diamond indenter having the same depth-area ratio as a Vickers diamond tip indenter. The fiber loading history involved an application of a predetermined constant loading rate to a maximum force followed by a constant unloading rate until $95 \%$ of the force was

* Nano Instruments Inc., Knoxville, TN. 
removed. This sequence was followed first by a hold segment, necessary for correction of thermal drift, and then by complete unloading. The magnitudes of the force and displacement were continuously measured during each segment of the loading procedure with resolutions of $2.4 \mu \mathrm{N}$ and $0.4 \mathrm{~nm}$, respectively. The maximum load capability of the instrument was $0.12 \mathrm{~N}$.

Table 1. Summary of Composite Systems Utilized in Interfacial Properties Study.

\begin{tabular}{|c|c|c|c|c|}
\hline Fiber & Matrix & Coating & Processing & Ref. \\
\hline $\begin{array}{l}\mathrm{SiC}^{\star} \\
\mathrm{SiC}^{\star}\end{array}$ & $\begin{array}{l}\text { LAS Glass }{ }^{\star \star} \\
\text { MDF Cement }\end{array}$ & $\begin{array}{c}\text { None } \\
\text { Stearic Acid }\end{array}$ & $\begin{array}{l}\text { Hot Pressed } \\
\text { Warm Pressed }\end{array}$ & $\begin{array}{c}11 \\
12,13\end{array}$ \\
\hline $\begin{array}{l}\operatorname{SiC}^{\star} \\
\text { Mullite }\end{array}$ & $\begin{array}{l}\text { SiC } \\
\text { Glass }\end{array}$ & $\begin{array}{c}\text { Graphite } \\
\text { BN }\end{array}$ & $\begin{array}{c}\text { CVI } \\
\text { Hot Pressed }\end{array}$ & $\begin{array}{l}14 \\
15 \\
\end{array}$ \\
\hline
\end{tabular}

* Nicalon fiber, Nippon Carbon Company, Tokyo, Japan. ** $\mathrm{Li}_{2} \mathrm{O}-\mathrm{Al}_{2} \mathrm{O}_{3}-\mathrm{SiO}_{2}$ Glass.

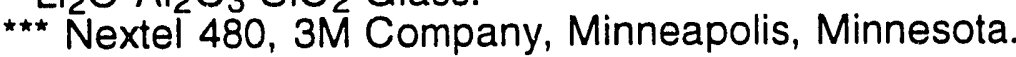

In order to generate fiber displacement, $u_{s}$, versus stress, $\sigma$, curves from the MPM data, the indenter penetration into the fiber, $u_{p}$, was first subtracted from the total displacement of the indenter $\left(u_{p}+u_{s}\right)$. The relationship between stress and $u_{p}$ was determined by applying the loading procedure to relatively large fibers which did not slide. In order to facilitate the subtraction of up from the total displacement versus stress curves, the stress dependence of $u_{p}$ was represented by two curve fitted polynomial expressions each describing the loading and unloading curves, respectively.

\section{RESULTS AND DISCUSSION}

Figure 2 illustrates the $\sigma-u_{s}$ data obtained for the SiC/LAS composite. The predicted curve in this figure was calculated using the early model by Hsueh. ${ }^{6}$ In this case, the Poisson's expansion of the fiber is used to account for the deviation of the experimental $u_{0} / u_{\max }$ ratio $(=0.35)$ from the value of 0.5 obtained for $v f=0$. The agreement between the predicted and experimental curves is quite good. The sliding resistance for this composite is characterized by the parameters $\mu(=0.09)$ and $\sigma R_{i r}(=21 \mathrm{MPa})$ instead of $\tau_{i}$, which varies along the sliding length in accordance with Eq. 3.

A key limitation of the predicted curve in Fig. 2 , is that it neglects the effect of the residual axial stress in the fiber, $\sigma R_{f z}$. As discussed above, when $\sigma R_{f z}$ is compressive, the relative fiber recovery during unloading will increase such that $u_{o} / u_{\max }$ decreases. One method for distinguishing hetween the effects of $\sigma \mathrm{f}_{\mathrm{fz}}$ and $v_{f}$ involves measuring $u_{0} / u_{\max }$ as a function of the peak stress ( $\sigma_{\max }$ in Fig. 1). ${ }^{16}$ As shown in Fig. 3 , the 


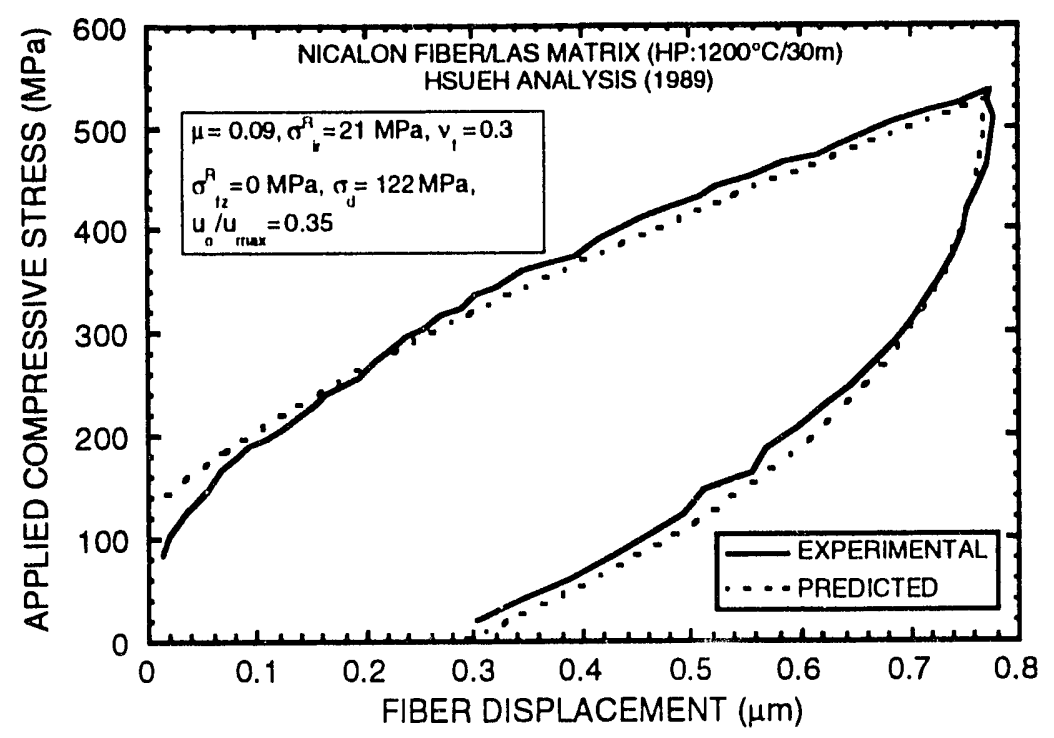

Figure 2. Typical Stress-Fiber Displacement Curve for the SiC/LAS Glass Composite.

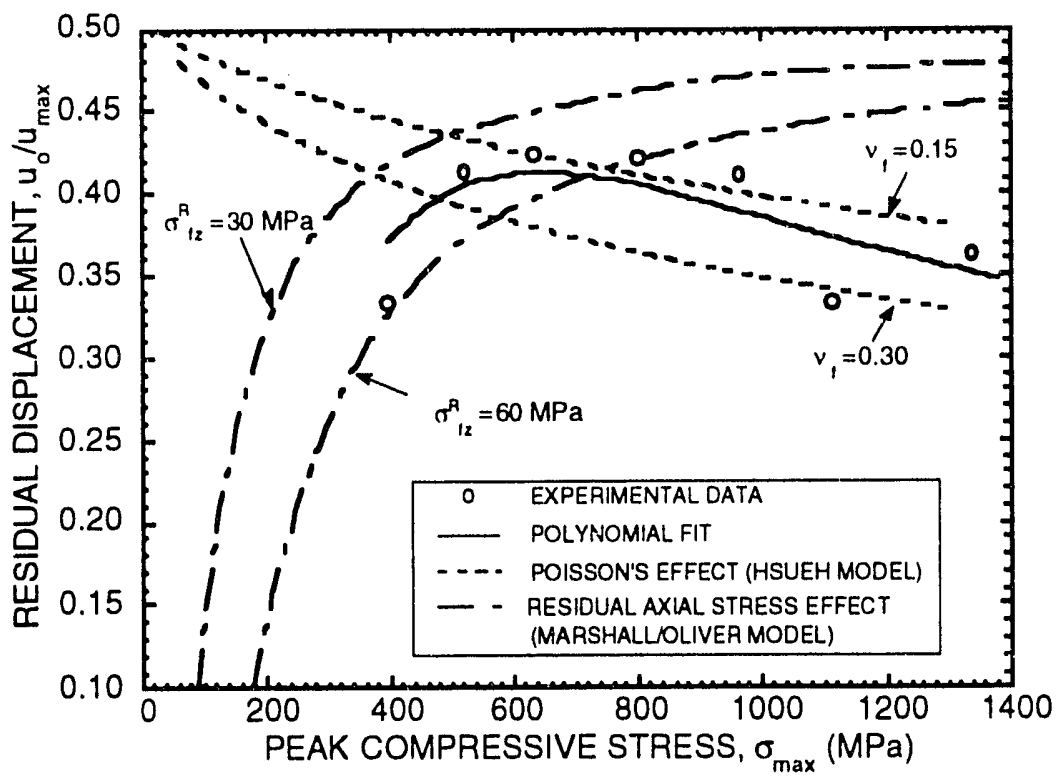

Figure 3. Effect of Peak Stress Upon the Relative Displacement Ratio for the SiC/LAS Glass Composite. Experimental data are compared with predictions based on the analyses of Hsueh and Marshall/Oliver. 
experimental values of $u_{0} / u_{\max }$ exhibit a maximum as $\sigma_{\max }$ is increased. This trend is quite consistent with the predicted curve based on the analyses of Hsueh 6 and Marshall/Oliver. ${ }^{5}$ The former analysis, which accounts for Poisson's effects only, was conducted for $\mu=0.09$ and $\sigma^{R_{i r}}=$ $-21 \mathrm{MPa}$ for $v f=0.3$ and $v f=0.15$. The Marshall/Oliver model, which ignores Poisson's effects, was used to predict the effect of $\sigma^{R_{f z}}$ upon the peak stress dependence of the relative residual displacement for both $\sigma_{\mathrm{fz}}=30 \mathrm{MPa}$ and $\sigma \mathrm{R}_{\mathrm{fz}}=60 \mathrm{MPa}$. The choice of these two $\sigma \mathrm{R}_{\mathrm{fz}}$ values was based upon the application of the Marshall model to the description of the experimental applied stress versus displacement data for the $\mathrm{SiC/LAS} \mathrm{composite.}$

The predicted curves in Fig. 3 reveal opposing trends in the effects of Poisson's ratio and residual axial stress upon the peak stress dependence of $u_{o} / u_{\max }$. Considering the curves generated for $\sigma R_{\mathrm{fz}}=$ $60 \mathrm{MPa}$ (Marshall model) and $v f=0.15$ (Hsueh model), it is evident that for $\sigma_{\max }<650 \mathrm{MPa}$, the residual axial stress dominates the relative residual displacement as reflected by the large deviation of the predicted $u_{o} / u_{\max }$ from the value of 0.5 which would result for $v f=0$ and $\sigma R_{f z}=$ $0 \mathrm{MPa}$. As $\sigma_{\max }$ exceeds $650 \mathrm{MPa}, u_{0} / u_{\max }$ is controlled by the Poisson's ratio effect. A similar opposing trend is exhibited by the experimental data, which are well-described by the Marshall model for $\sigma_{\max }<650 \mathrm{MPa}$ and the Hsueh model for $\sigma_{\max }>650 \mathrm{MPa}$. The predicted curves in Fig. 3 also illustrate the effects of the magnitudes $\sigma^{R_{f z}}$ and $\mathrm{vf}$ upon the relative recovery during fiber sliding. In the case of the Marshall model, a small decrease in $\sigma \mathrm{R}_{\mathrm{fz}}$ shifts the $\sigma_{\max }$ versus $u_{0} / u_{\max }$ curve to the left thereby lowering the critical transition stress from $650 \mathrm{MPa}$ to $420 \mathrm{MPa}$. In the Hsueh model, an increase in vf increases the extent of the Poisson's ratio effect. The transition stress is again lowered to approximately $550 \mathrm{MPa}$.

The residual axial stress in the fiber plays an even more important role in the SiC/MDF cement composite. Using the Marshall/Oliver analysis, $\sigma R_{\mathrm{fz}}$ is estimated to be 66 and $129 \mathrm{MPa}$ for the stearic acid and silane coated fibers, respectively (Figs. $4 a$ and b). For the latter specimen, the fiber recovery upon unloading is greater than the displacement duririg loading $\left(u_{o} / u_{\max }=-0.31\right)$. Based on an analysis similar to that used in Fig. 3, Poisson's ratio effects are expected to be negligible. ${ }^{10}$

A typical stress-displacement curve for the mullite/glass composite is shown in Fig. 5. Even with the $0.2 \mu \mathrm{m}$ BN coating, sliding in this system was quite limited as evidenced by a relatively high value of $\tau_{i}$ (65 MPa). When no coating was present, sliding could not be measured. This difference in sliding characteristics is consistent with previous studies which showed a marked improvement in mechanical performance when the BN coating was applied to the fibers. ${ }^{15}$

The utilization of the interfacial properties in the calculation of the macro-mechanical behavior of the SiC/SiC composite is illustrated in Fig 6. The interfacial sliding shear stress for this system $\left(\tau_{i}=25 \mathrm{MPa}\right)$ 

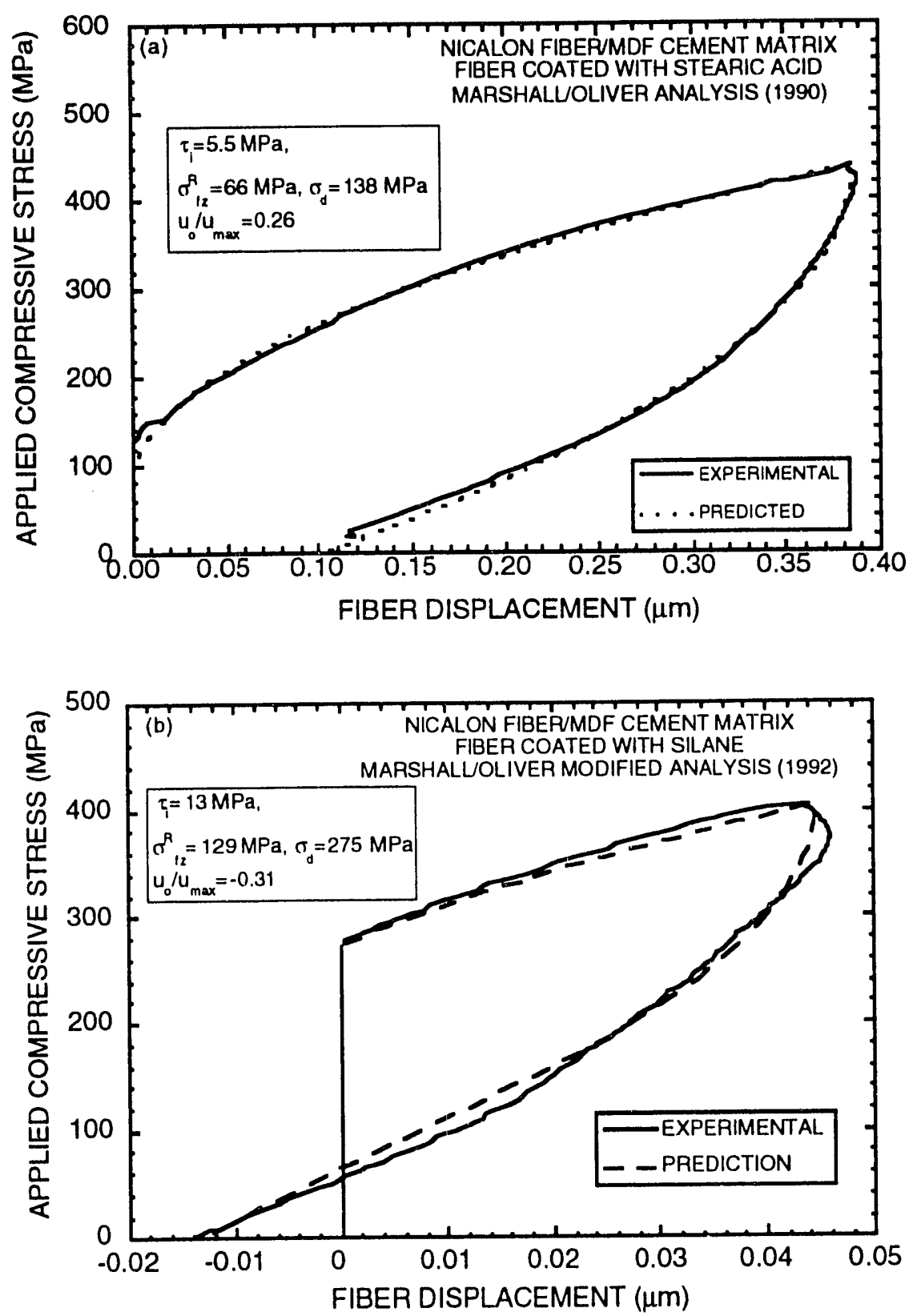

Figure 4. Stress-Fiber Displacement Curves for the SiC/MDF Cement Composite: (a) Fibers Coated with Stearic Acid and (b) Fibers Coated with Silane. 


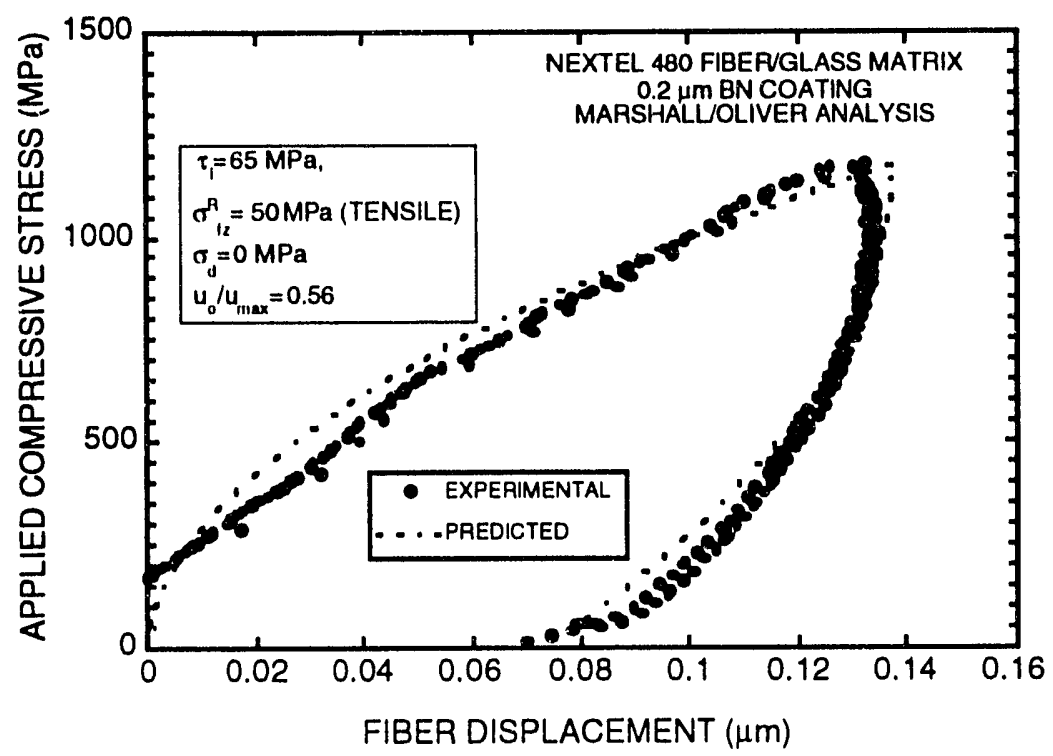

Figure 5. Typical Stress-Fiber Displacernent Curve for the Mullite/Glass Glass Composite.

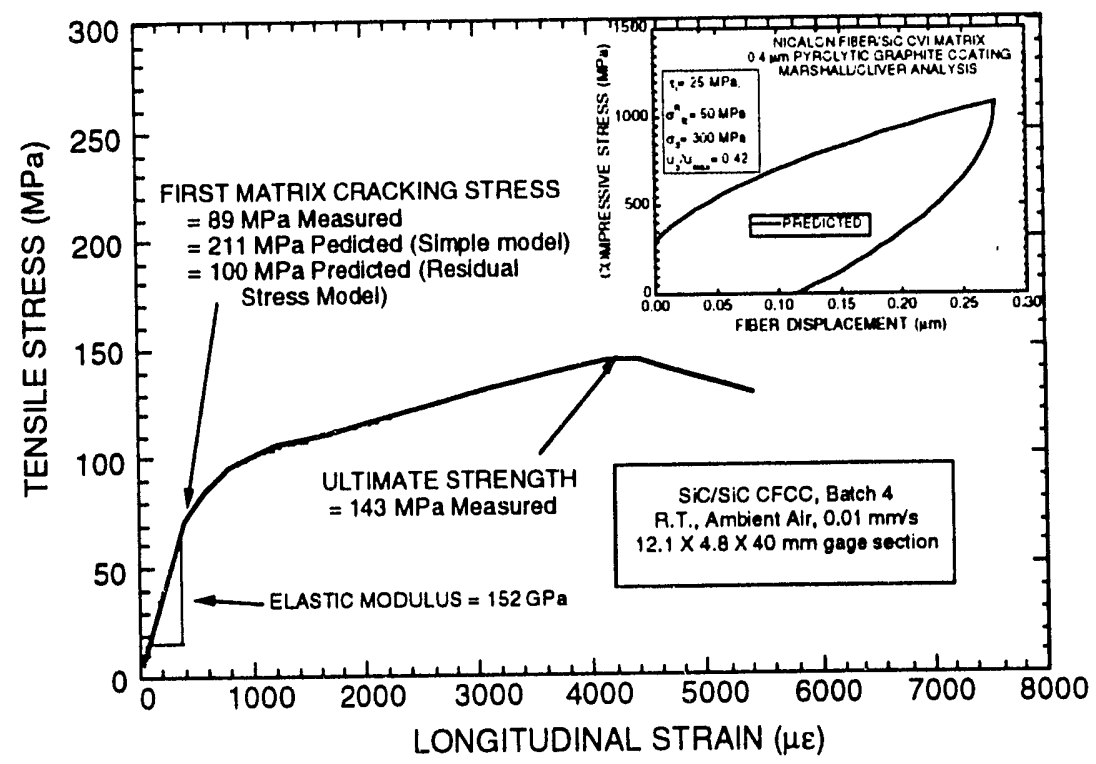

Figure 6. Comparison of Experimentally-Measured and Predicted Values of the First Matrix Cracking Stress in the SiC/SiC Composite. 
was used in conjunction with Eqs. 1 and 2 to estimate the first matrix cracking stress. Values for the other parameters were as follows: $r=$ $8.5 \mu \mathrm{m}, E_{f}=150 \mathrm{GPa}, E_{m}=350 \mathrm{GPa}, \gamma_{m}=15 \mathrm{~J} / \mathrm{m}^{2}$, and $V_{f}=0.41$. Using equations given in Ref. 17 in conjunction with the predicted value of $\sigma \mathrm{R}_{\mathrm{fz}}$ (=50 MPa), the residual axial stress in the matrix was estimated to be $35 \mathrm{MPa}$ (tensile). As indicated in Fig. 6, reasonable agreement between experimental and predicted values of $\sigma_{\mathrm{mu}}$ could only be obtained if the residual axial stress in the matrix was included in the analysis (Eq. $1 \mathrm{~b}$ ). The fact that the predicted value of $100 \mathrm{MPa}$ exceeds the experimental value of $89 \mathrm{MPa}$ may be a result of neglecting the effects of fiber debonding in the calculation of $\sigma_{\mathrm{mu}}$.

\section{CONCLUSIONS}

The push-in studies involving the MPM provided reasonable measurements of fiber sliding for those systems in which both the fiber diameters were small ( $<25 \mu \mathrm{m}$ diameter) and the values of $\tau_{i}$ and $\sigma_{d}$ were low $\left(\tau_{i}<50 \mathrm{MPa}\right.$ and $\left.\sigma_{\mathrm{d}}<0.5 \sigma_{\max }\right)$. When these conditions were not met as in the case of the mullite/glass composites, the uncertainty in the polynomial fits used to describe the $\sigma-u_{p}$ relationship constituted a major source of error in the estimates of the interfacial properties. The reduction of this error would have required the use of either higher peak loads or a small flat-bottomed indenter probe to eliminate the contribution of $u_{p}$ to the overall sliding.

The data generated for the SiC/LAS and SiC/MDF composites indicated that both Poisson's ratio and the residual axial stress in the fiber could have a significant effect upon the sliding characteristics. The relative contribution of each of these parameters could be determined by measuring the relative residual displacement as a function of the peak stress. In particular, below a critical peak stress, $u_{0} / u_{\max }$ was primarily a function of $\sigma^{R_{f z}}$ with $u_{0} / u_{\max }$ decreasing as the peak stress decreased. Above the critical peak stress, Poisson's expansion of the fiber controlled the value of $u_{0} / u_{\max }$ with $u_{0} / u_{\max }$ decreasing as the peak stress increased.

Although the models examined in this study provided good descriptions of the stress-displacement characteristics associated with the various composite systems, additional model refinements will be required for the analysis of real composite systems. For example, attention must be given to the treatment of more complex fiber architectures. These models must also account for anisotropy of the elastic properties. Finally, the shear-lag analysis, which is fundamental to most of the existing models, must be extended to three component systems involving fiber, coating, and matrix. 


\section{REFERENCES}

(1) Chun-Hway Hsueh, "Requirements of Frictional Debonding at Fiber/Matric Interfaces for Tough Ceramic Composites," Composites Eng., 2 [8] 655-63 (1992).

(2) B. B. Marshall and A. G. Evans, "The Influence of Residual Stress on the Toughness of Reinforced Brittle Materials," Mater. Forum, 11, 30412 (1988).

(3) B. Budiansky, J. W. Hutchinson, and A.G. Evans, "Matrix Fracture in Fibre-Reinforced Ceramics," J. Mech. Phys. Solids, 34 [2] 167-189 (1986).

(4) D. B. Marshall and W. C. Oliver, "Measurement of Interfacial Mechanical Properties in Fiber-Reinforced Ceramic Composites," J. Am. Cer. Soc., 70 [8] 542-548 (1987).

(5) D. B. Marshall and W. C. Oliver, "An Indentation Method for Measuring Residual Stresses in Fiber Reinforced Ceramics," Mat. Sci. Eng. , A126, 95-103 (1990).

(6) C. H. Hsueh, M. K. Ferber, and P. F. Becher, "StressDisplacement Relation of Fiber for Fiber-Reinforced Ceramic Composites During (Indentation) Loading and Unloading," J. Mater. Res., 4 [6] 152937 (1989).

(7) C. H. Hsueh, "Evaluations of Interfacial Properties of FiberReinforced Ceramic Composites using Mechanical Properties Microprobe," in review, Journal of the American Ceramic Society.

(8) R. J. Kerans and T. A. Parthasarathy, "Theoretical Analysis of the Fiber Pullout and Pushout Tests," J. Am. Cer. Soc., 74 [7] 1585-96 (1991).

(9) D. B. Marshall, "Analysis of Fiber Debonding and Sliding Experiments in Brittle Matrix Composites," Act Metall. Mater, 40 [3] 42741 (1992).

(10) C. H. Hsueh and M. K. Ferber, "Evaluations of Residual Axial Stresses and Interfacial Friction in Nicalon Fiber-Reinforced MacroDefect-Free Cement Composites," in press, Journal of Materials Science.

(11) J. R. VanValzah, "Processing, Interfacial Characterization, and Mechanical Property Evaluation of SiC Fiber/Li2 $\mathrm{O}-\mathrm{Al}_{2} \mathrm{O}_{3}-\mathrm{SiO}_{2}$ Glass Matrix Composites," M.S. Thesis, Univ. of Illinois, Urbana, IL, 1986. 
(12) M. K. Ferber, A. A. Wereszczak, D. Hansen, and J. Homeny, "Evaluation of the Interfacial Mechanical Properties in SiC FiberReinforced MDF Cement Composites, " in press, Composite Science and Technology.

(13) D. H. Hansen, "Interfacial Characterization of SiC Fiber/MDF Matrix Composites," M.S. Thesis, Univ. of Illinois, Urbana, IL, 1990.

(14) M. J. Jenkins and M. K. Ferber, unpublished work, Oak Ridge National Laboratory, May 1992.

(15) R. U. Vaidya, J. Fernando, K. K. Chawla, and M. K. Ferber, "Effect of Fiber Coating on the Mechanical Properties of a Nextel 480 Fiber Reinforced Glass Matrix Composite, "Matl. Sci. and Eng. A150, $161-9$ (1992).

(16) C. H. Hsueh, M. K. Ferber, and A. A. Wereszczak, "The Relative Residual Fiber Displacement after Indentation Loading and Unloading of Fiber-Reinforced Ceramic Composites, " in publication, Journal of Material Science.

(17) Chun-Hway Hsueh, Paul F. Becher, and Peter Angelini, "Effects of Interfacial Films on Thermal Stresses in Whisker-Reinforced

Ceramics," J. Am. Cer. Soc., 71 [11] 929-33 (1988). 

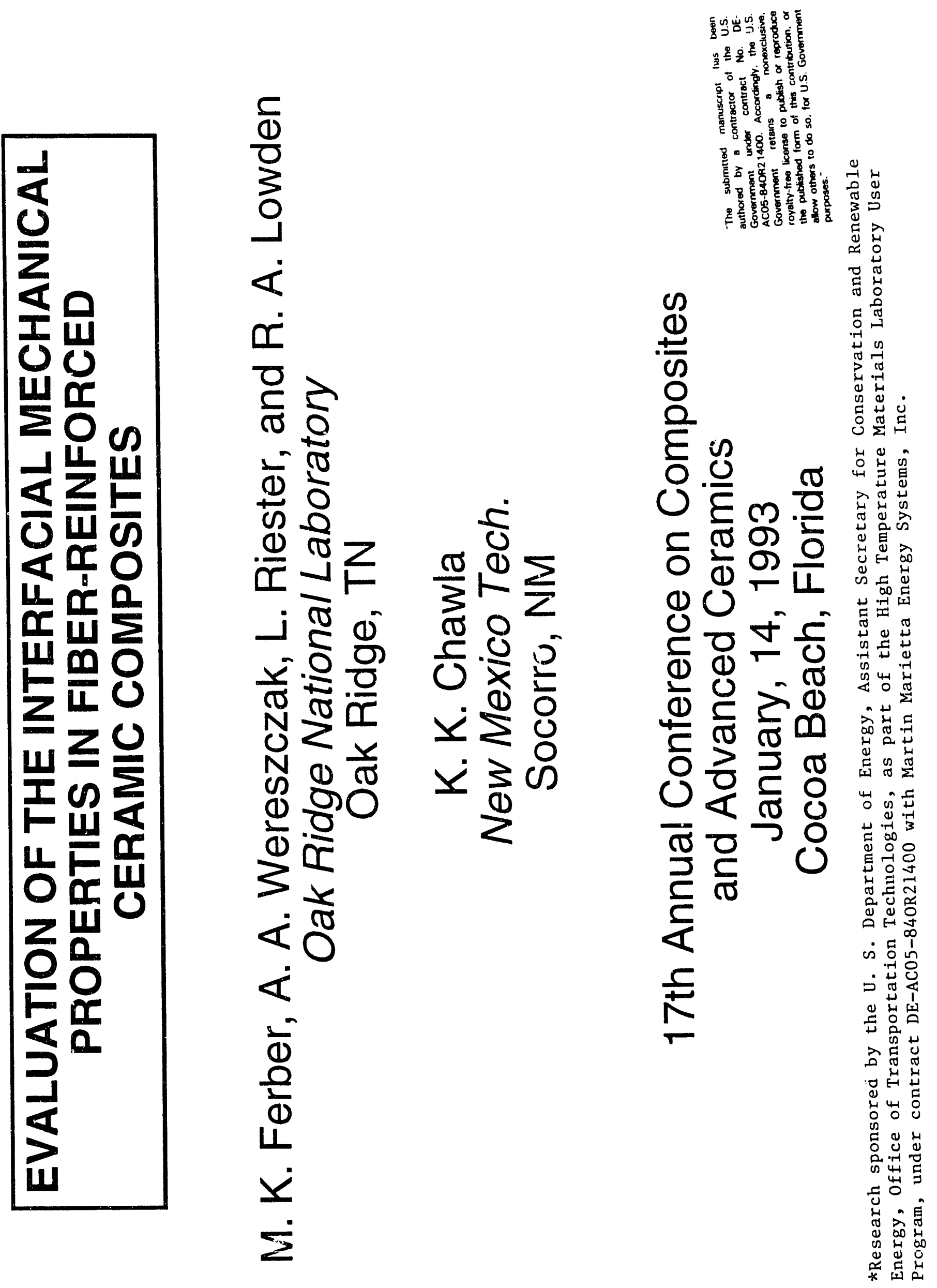


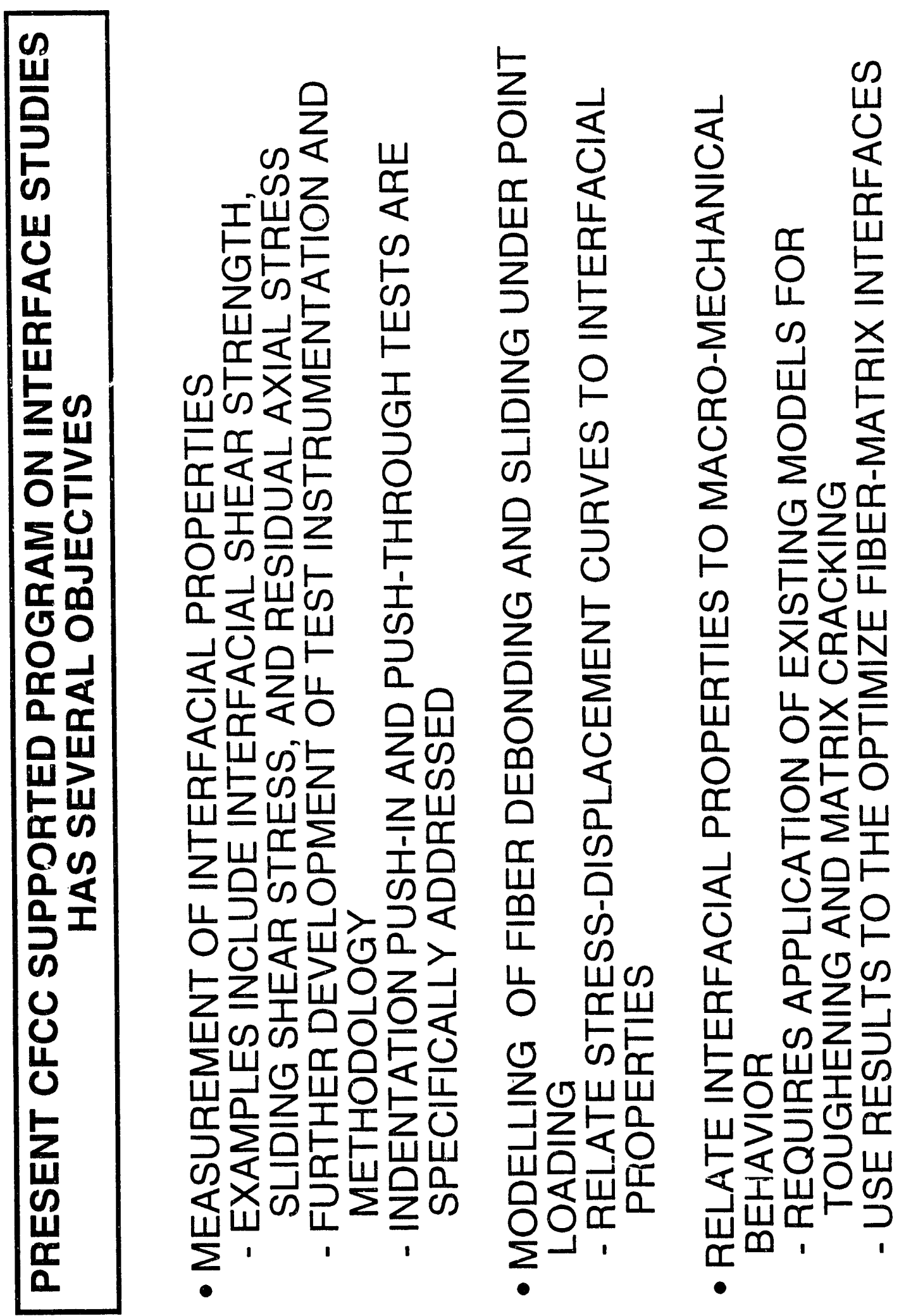




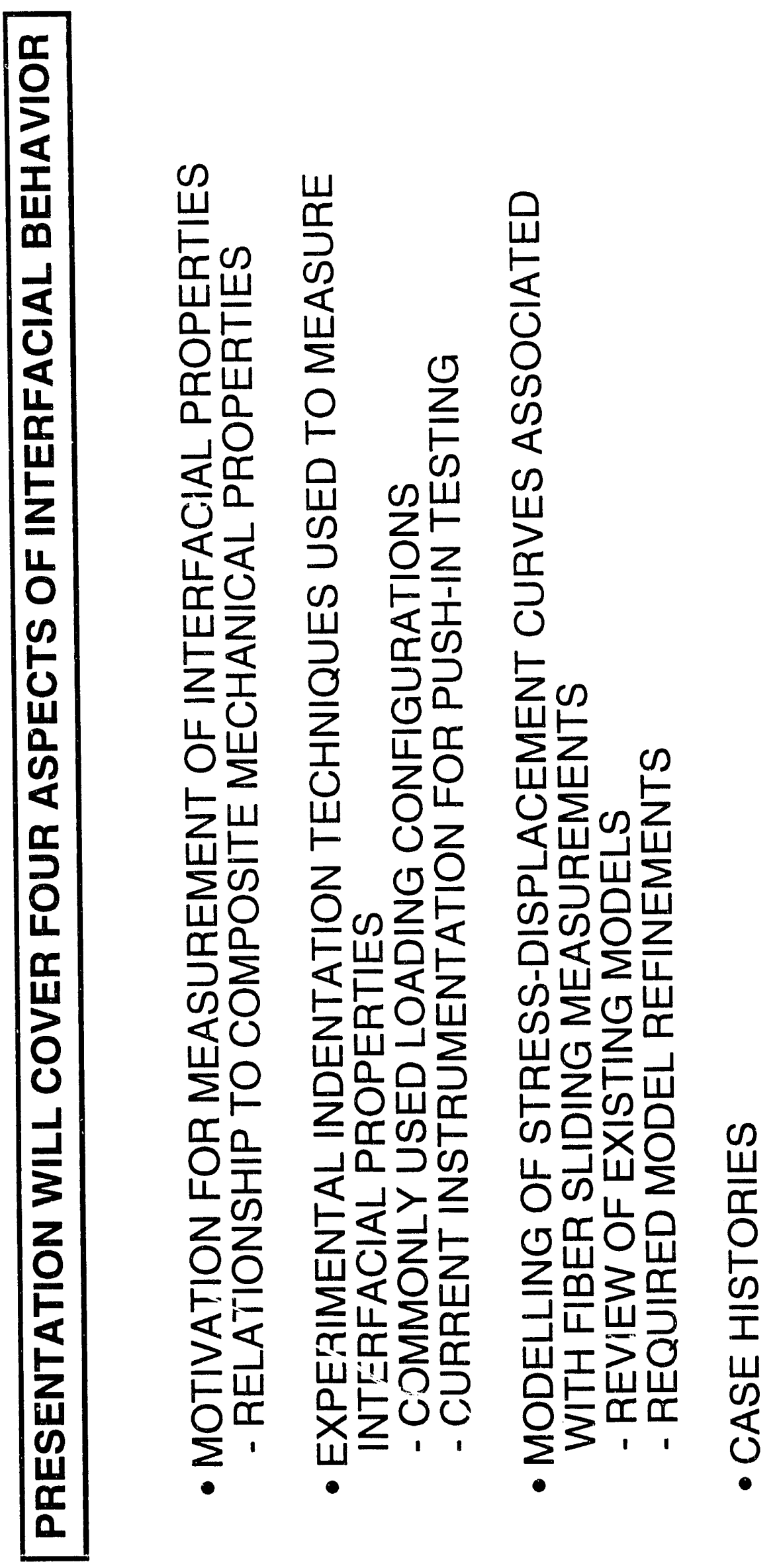




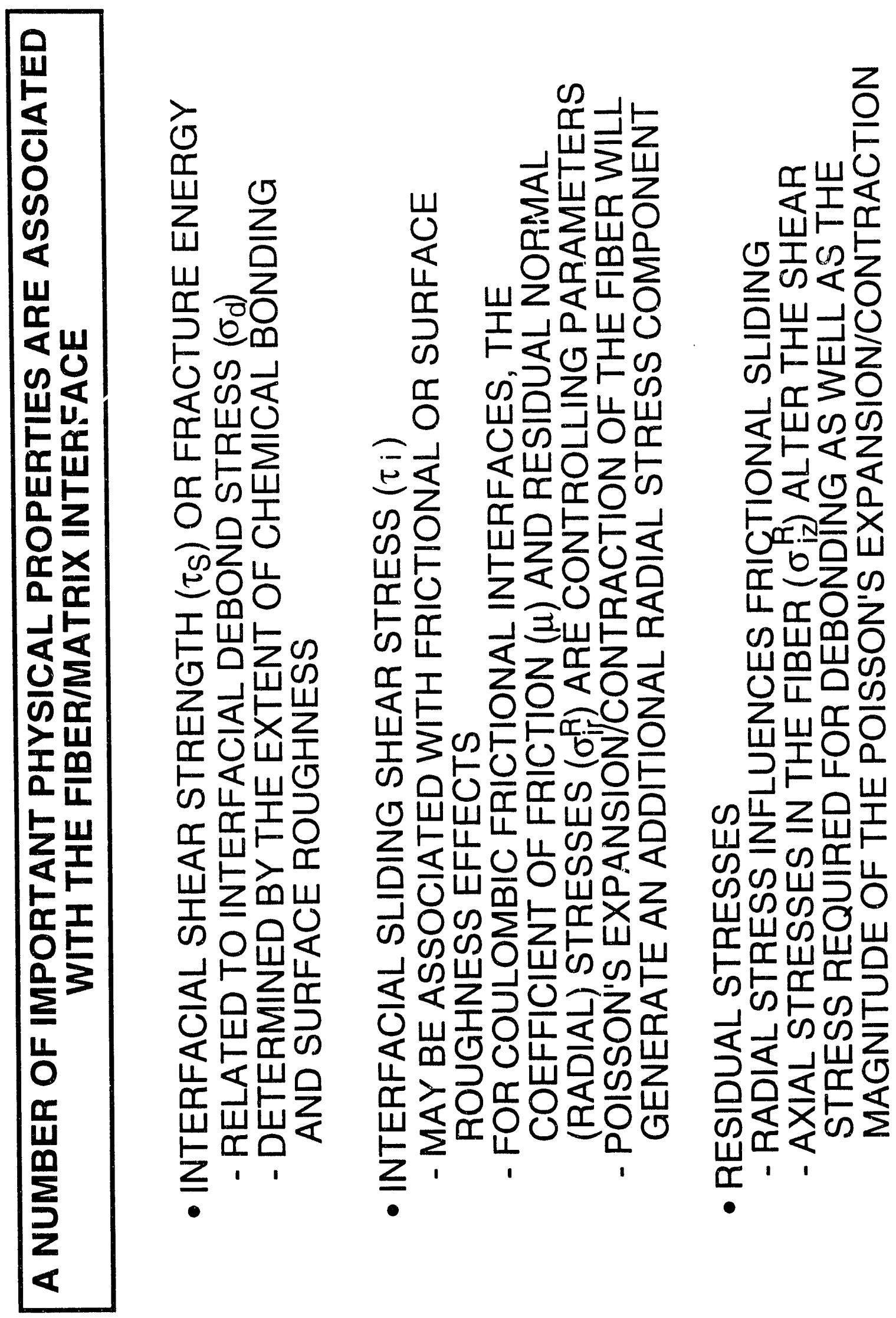




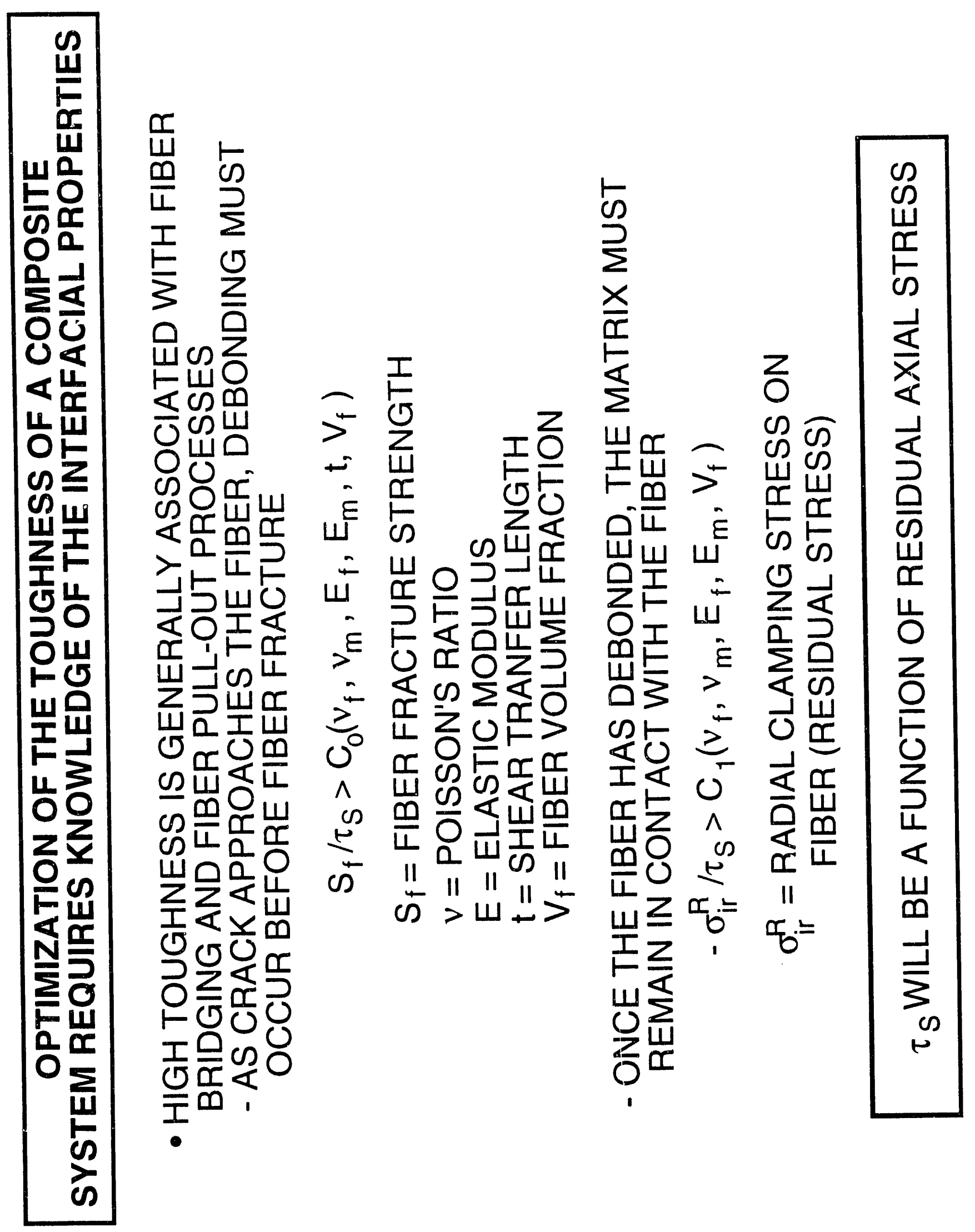




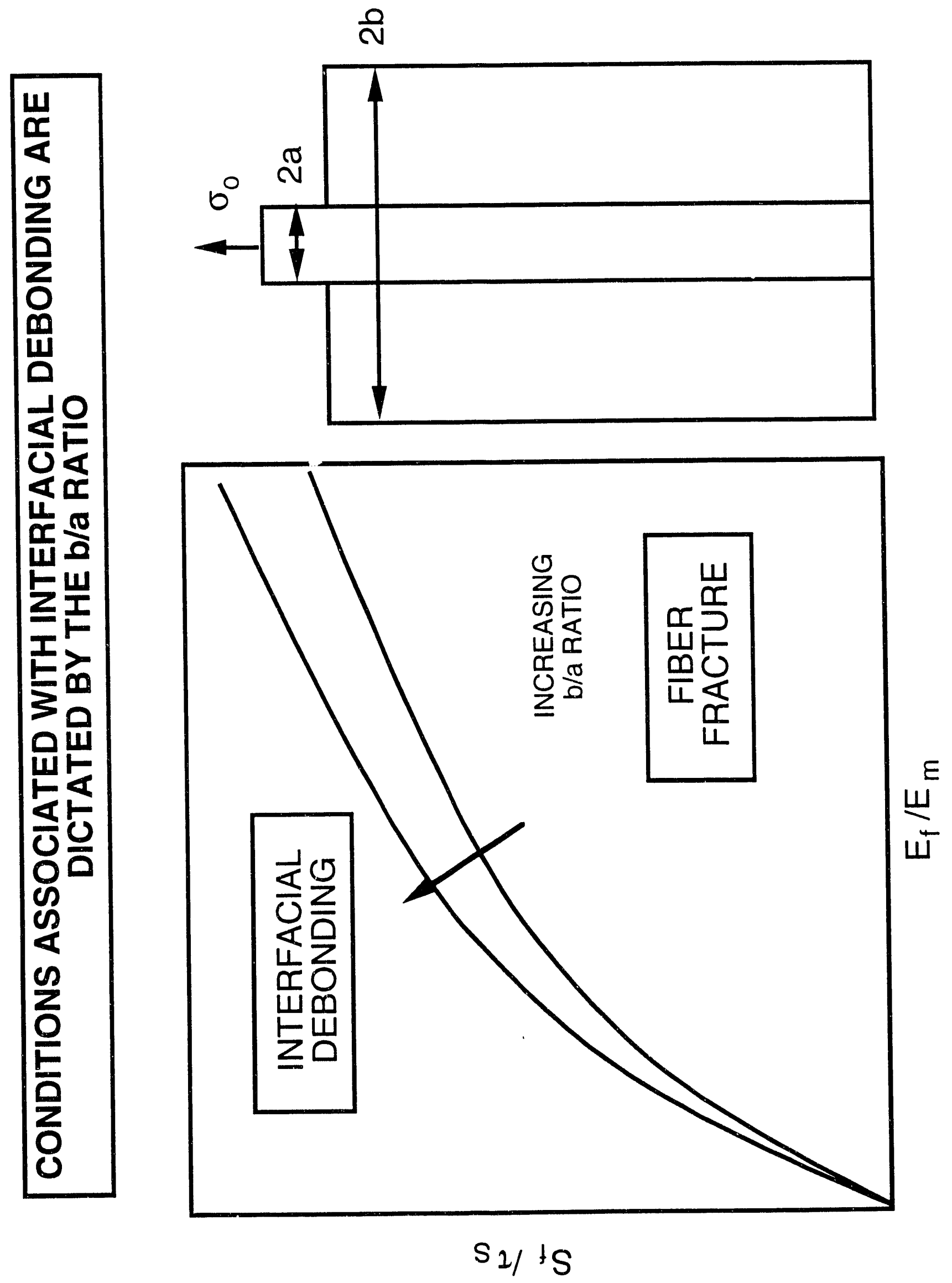




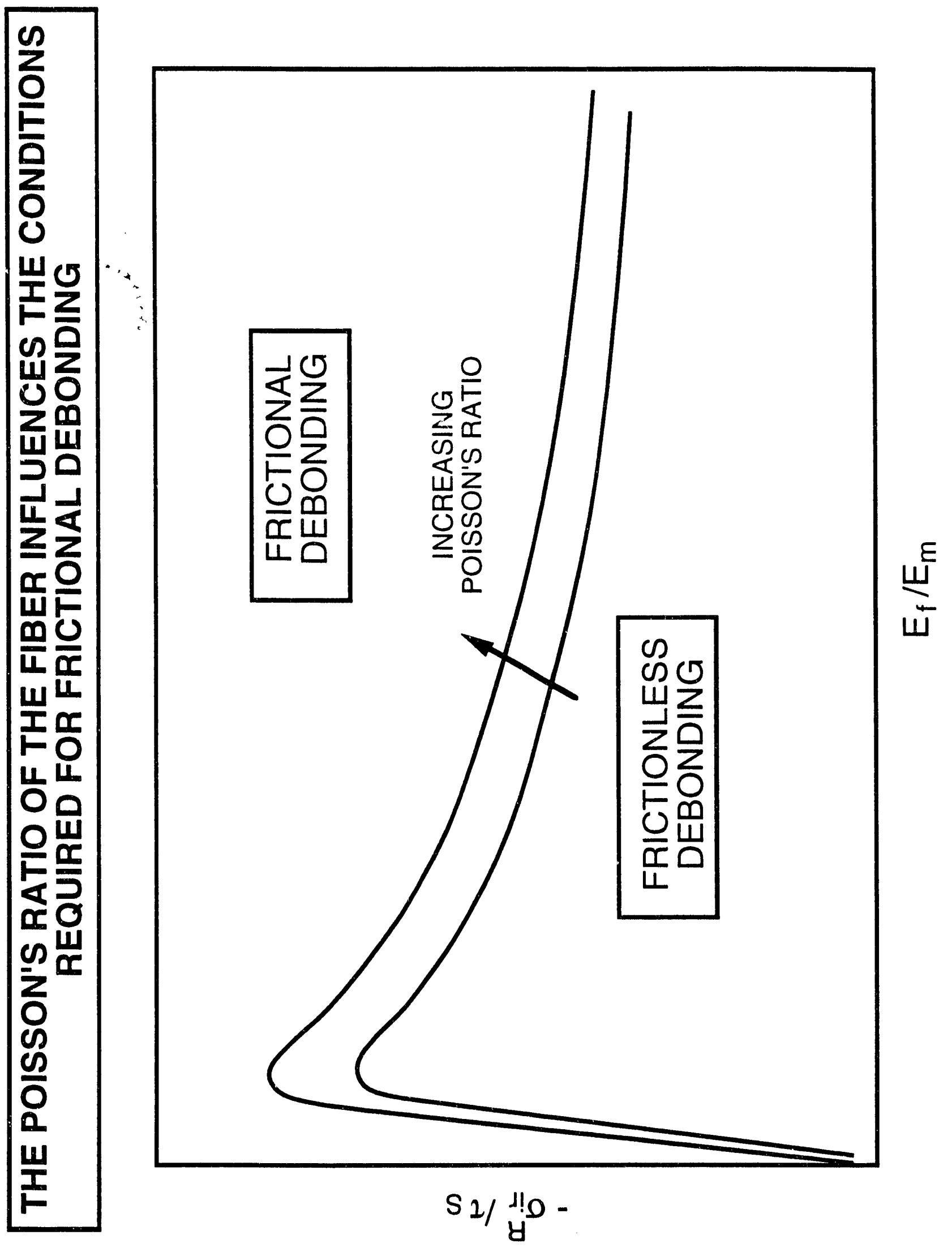




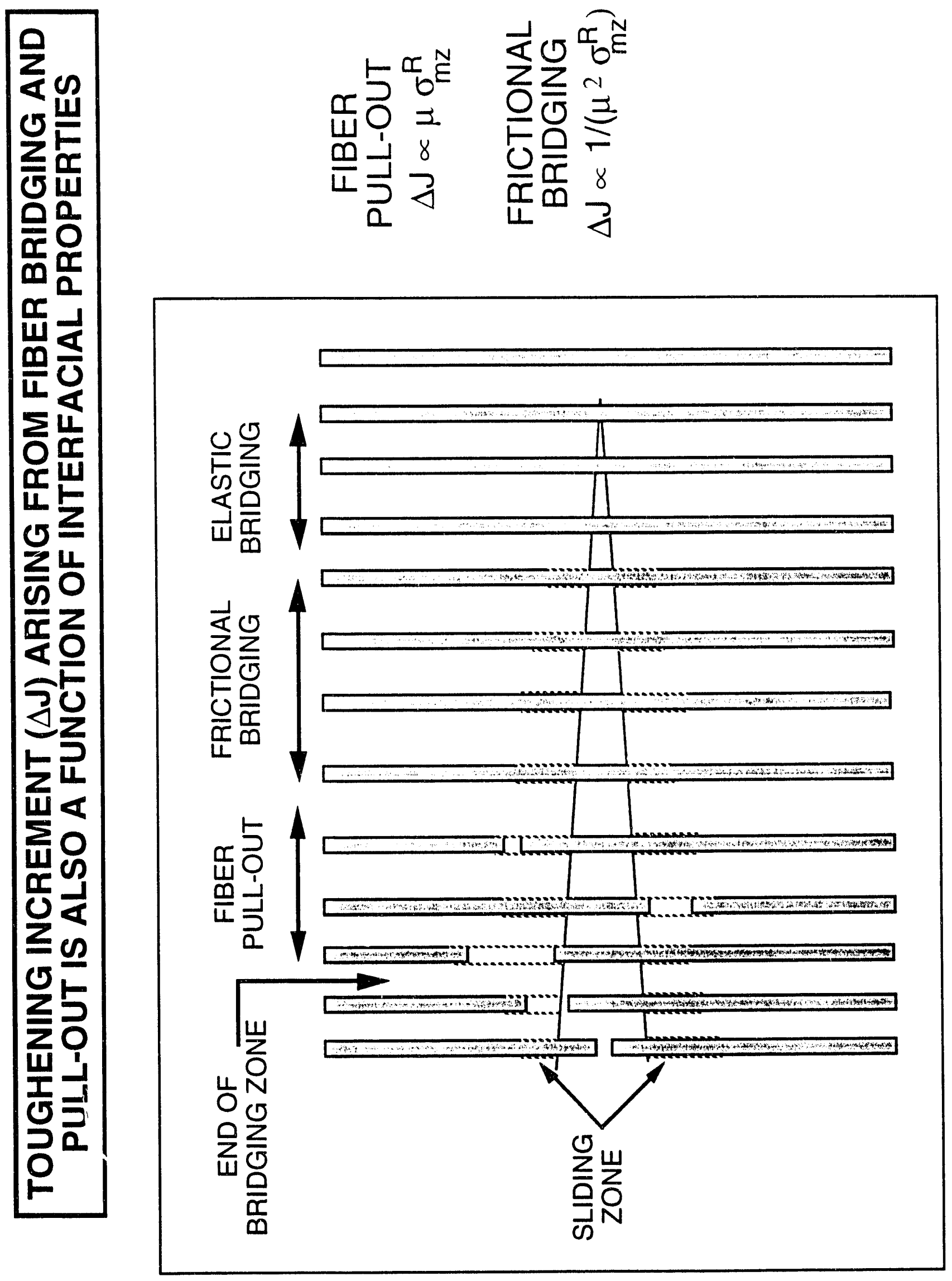




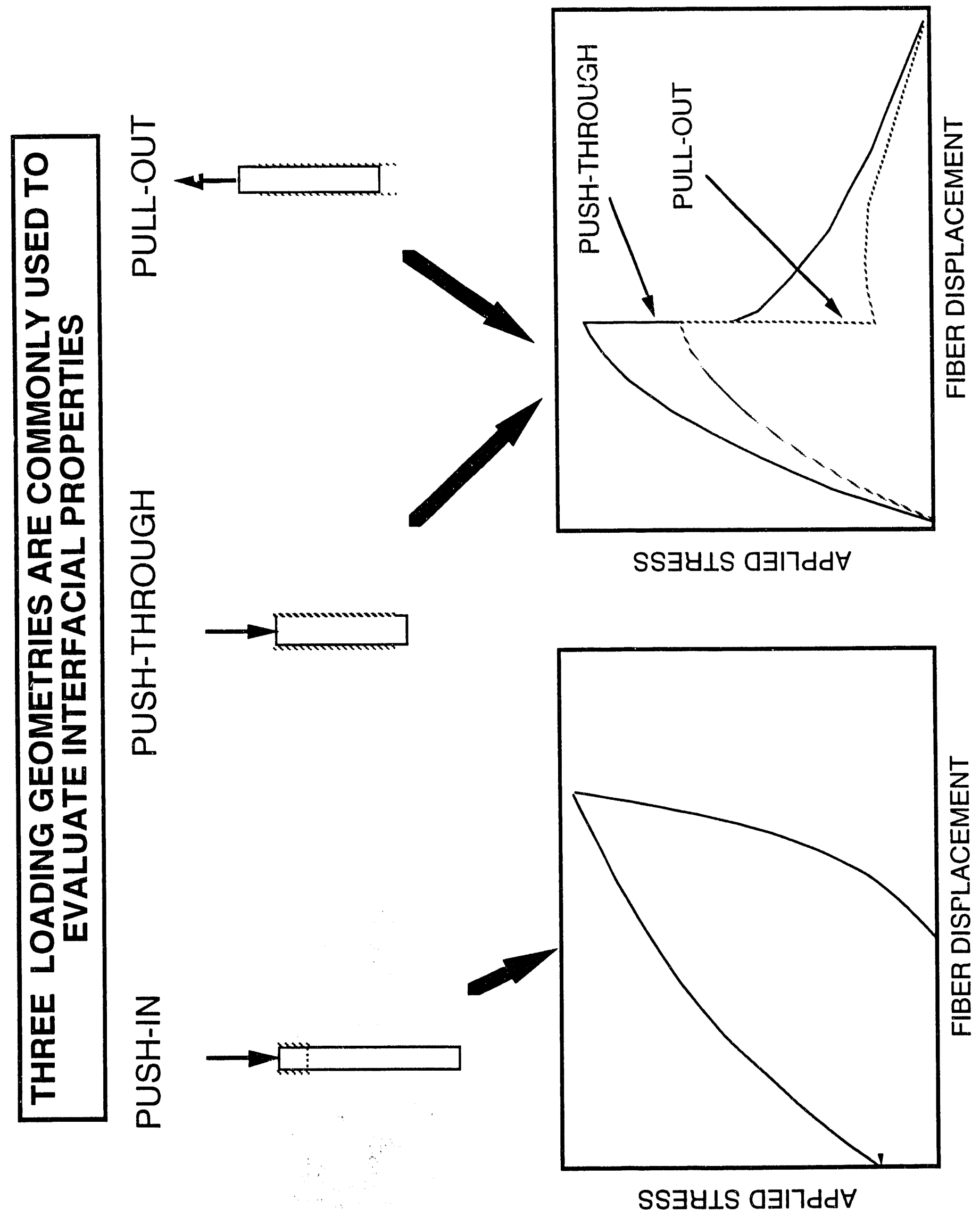



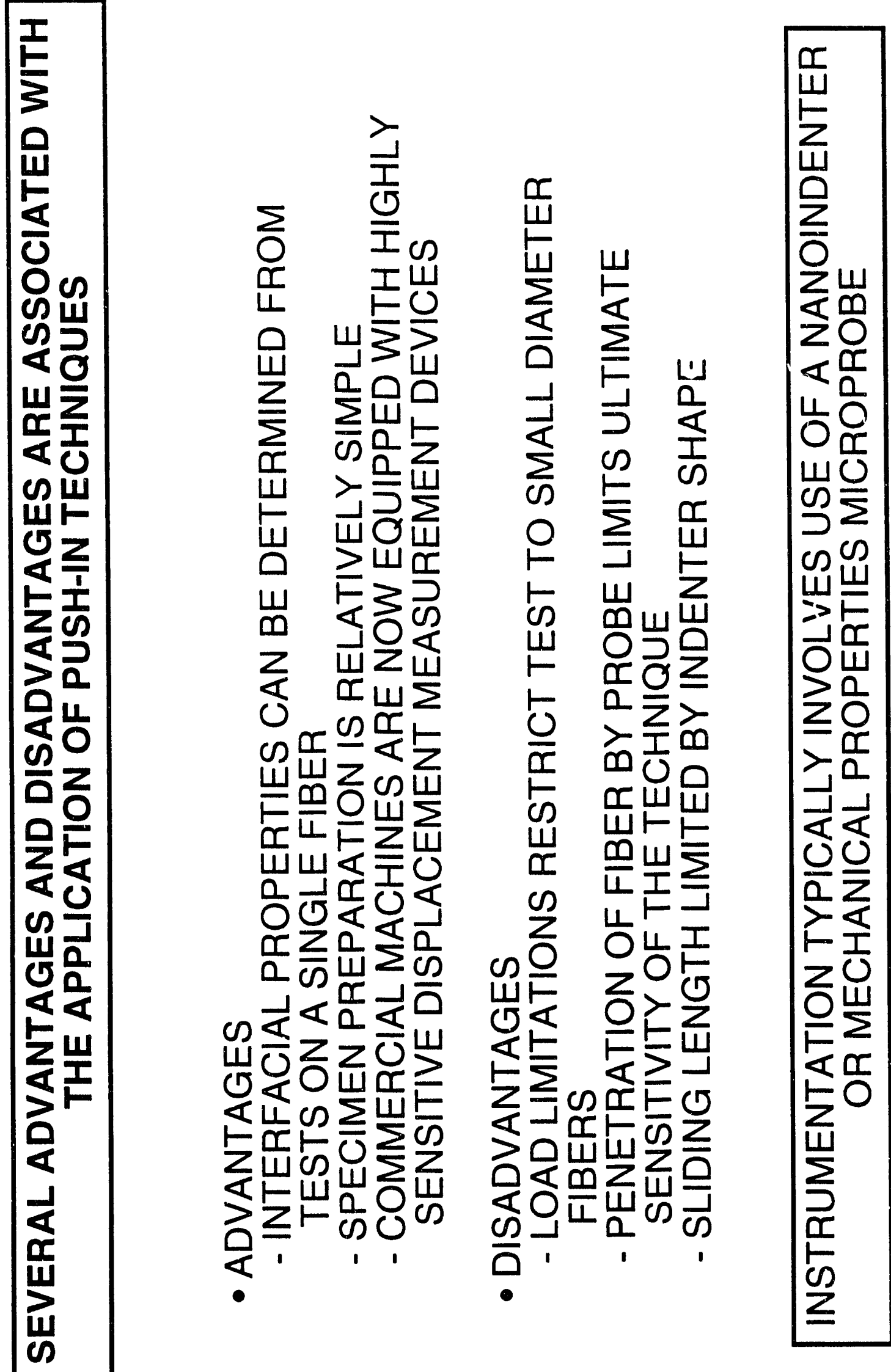

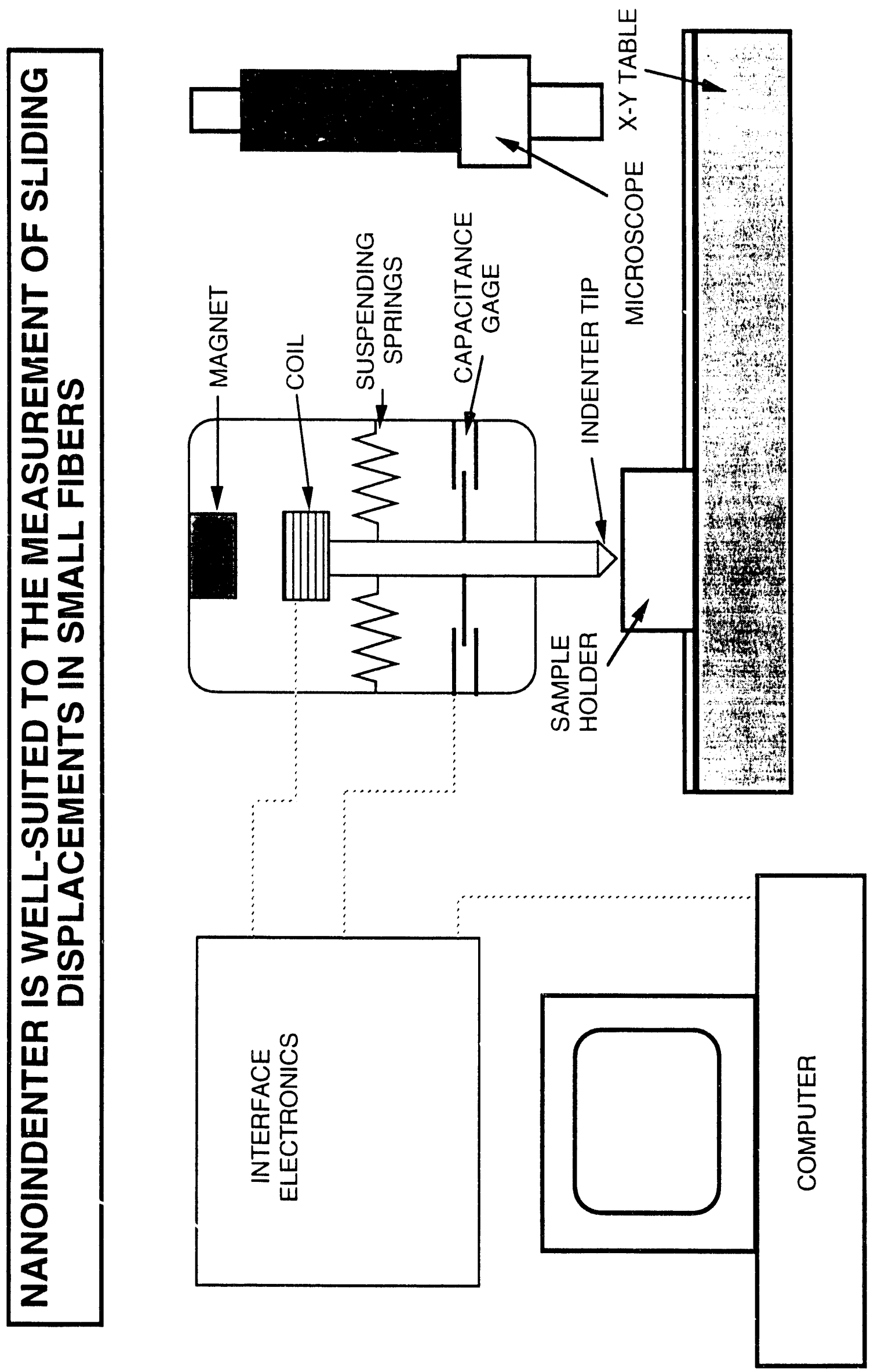


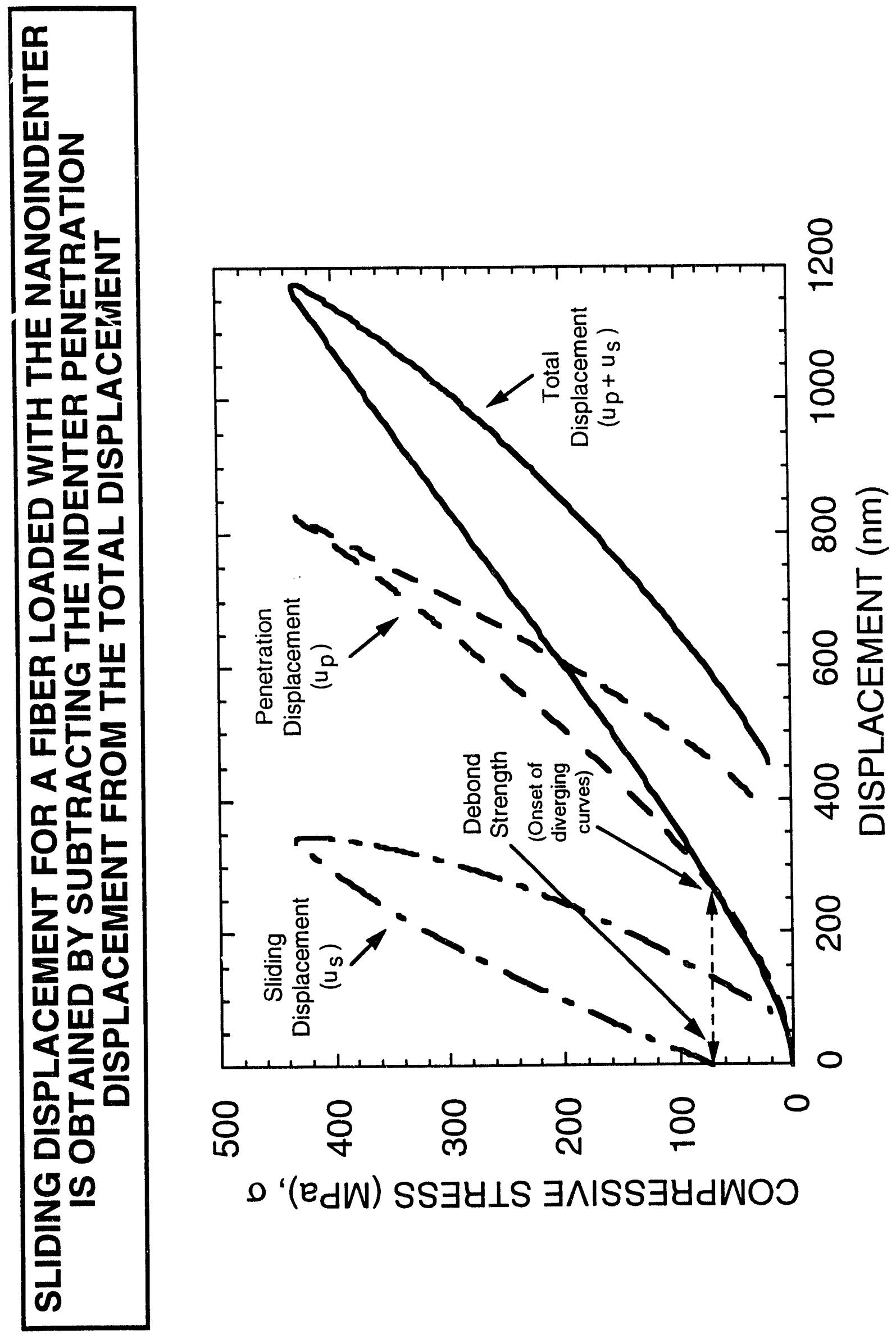




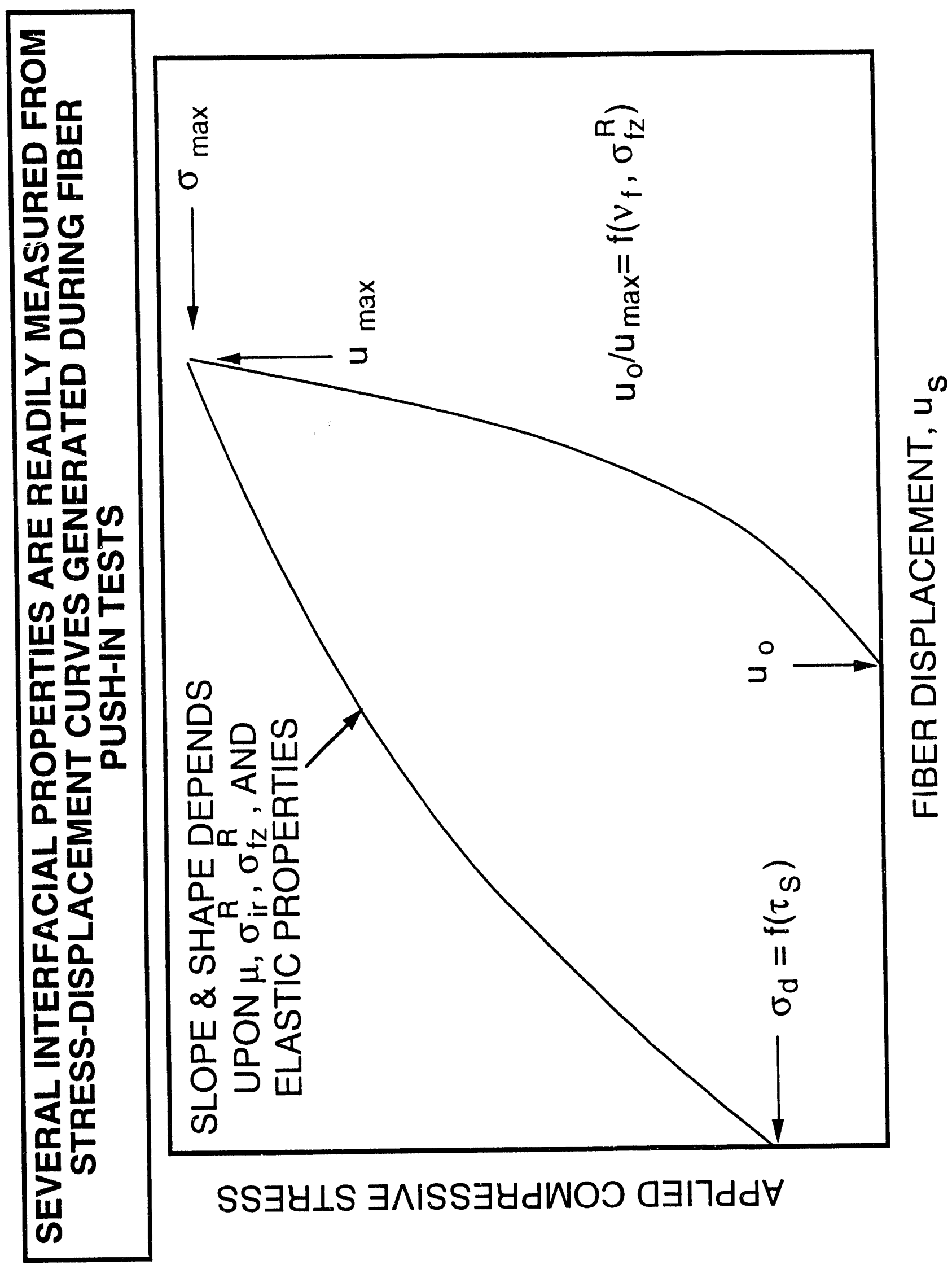




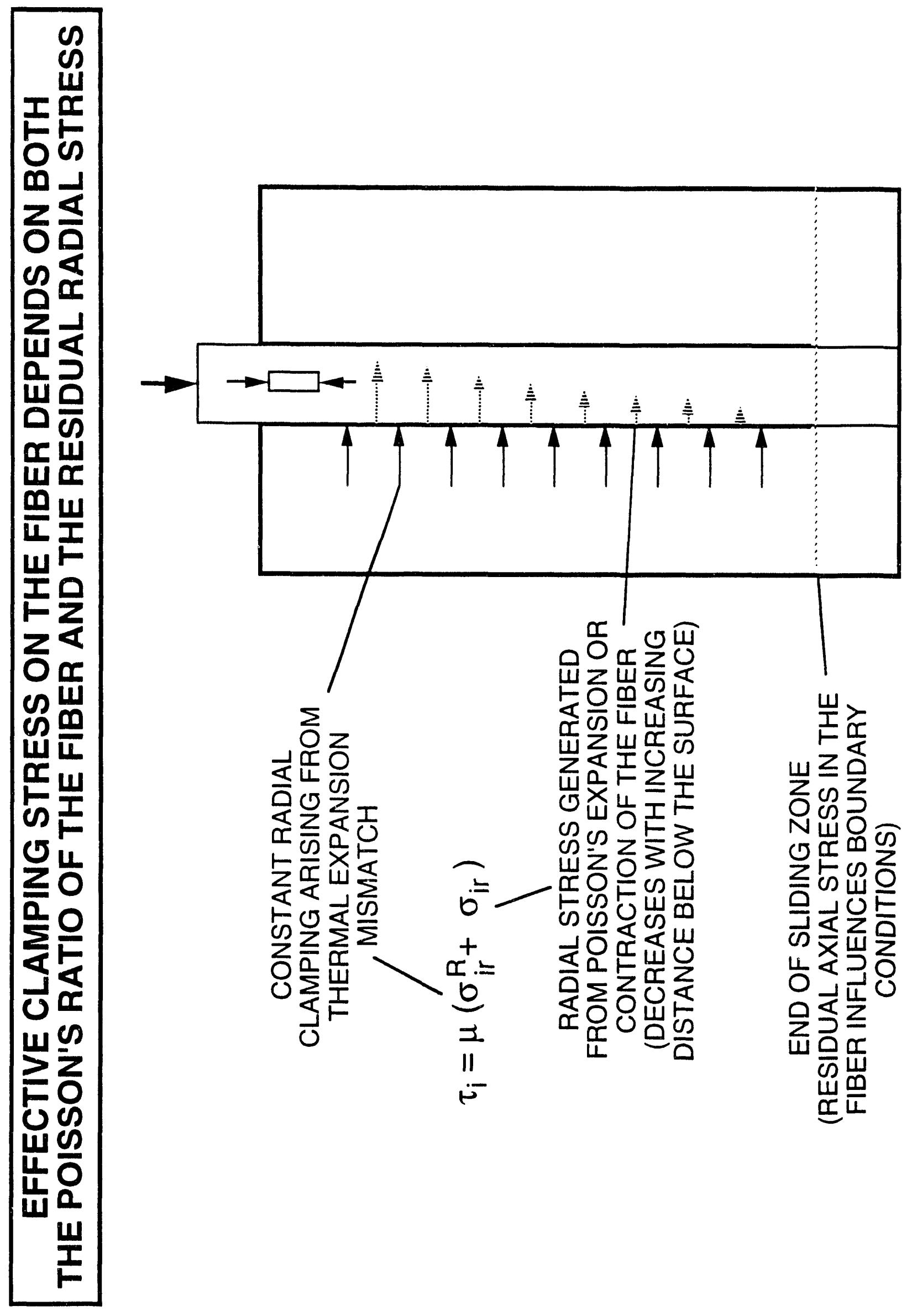



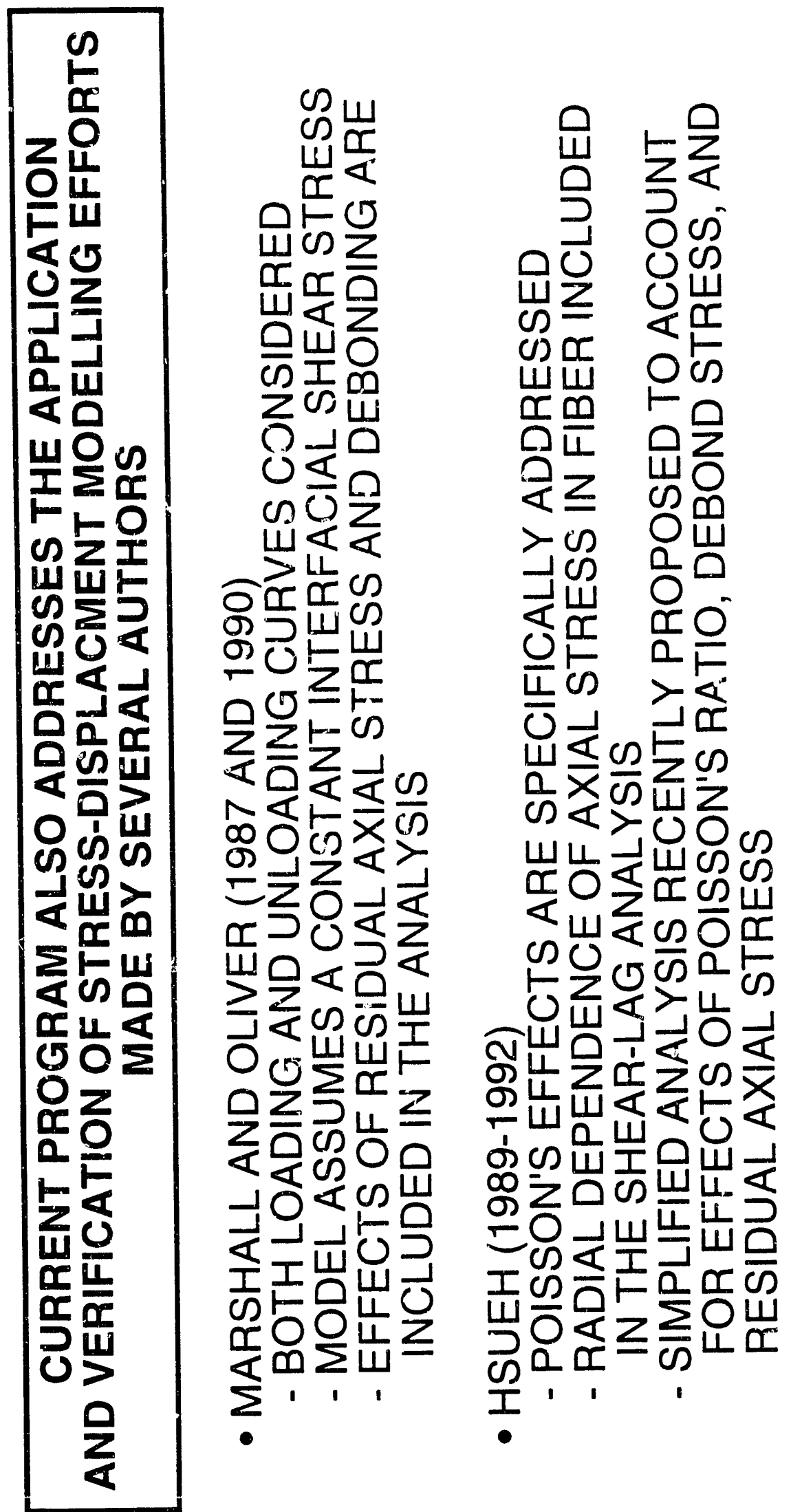

$\stackrel{\sim}{Z N}$

○ய

$\infty \sum$

Z

Q I

\&

口?

लिख

ヘ山

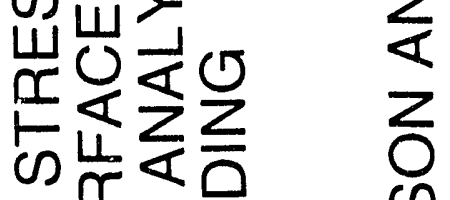

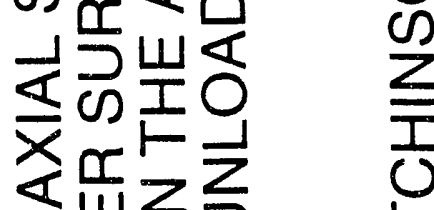

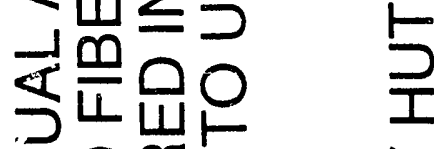

ต号品 文

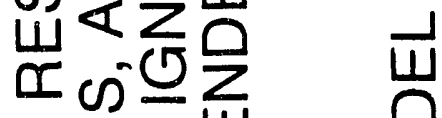

エஸ山上

눓

丩近正

$\bar{\sigma} \operatorname{cs}$

ब르를

구요

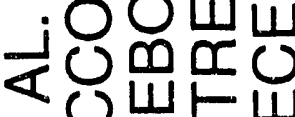

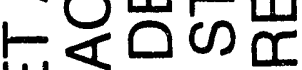

क너ㅇㅡㅡ

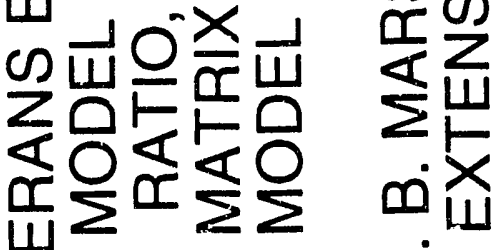




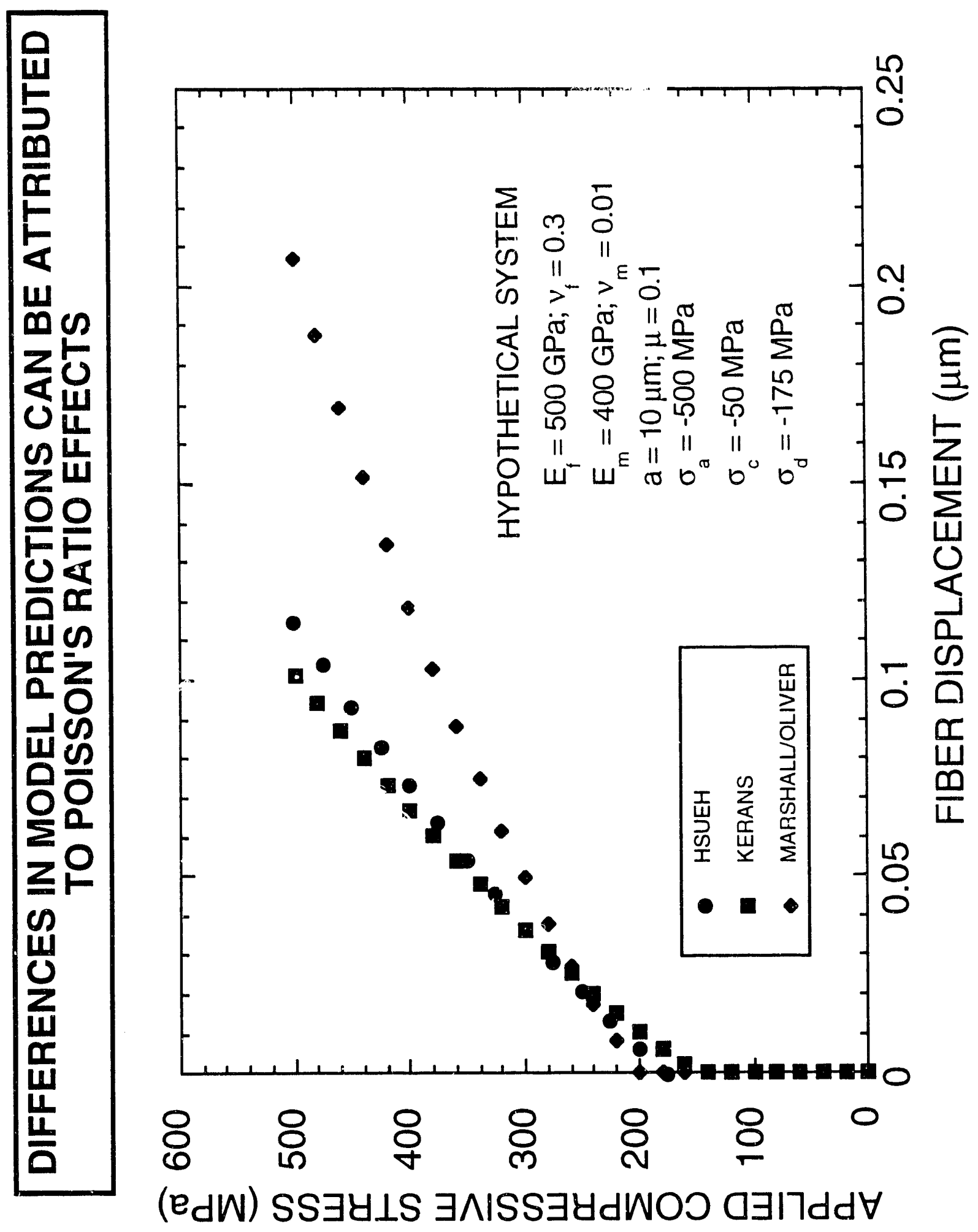




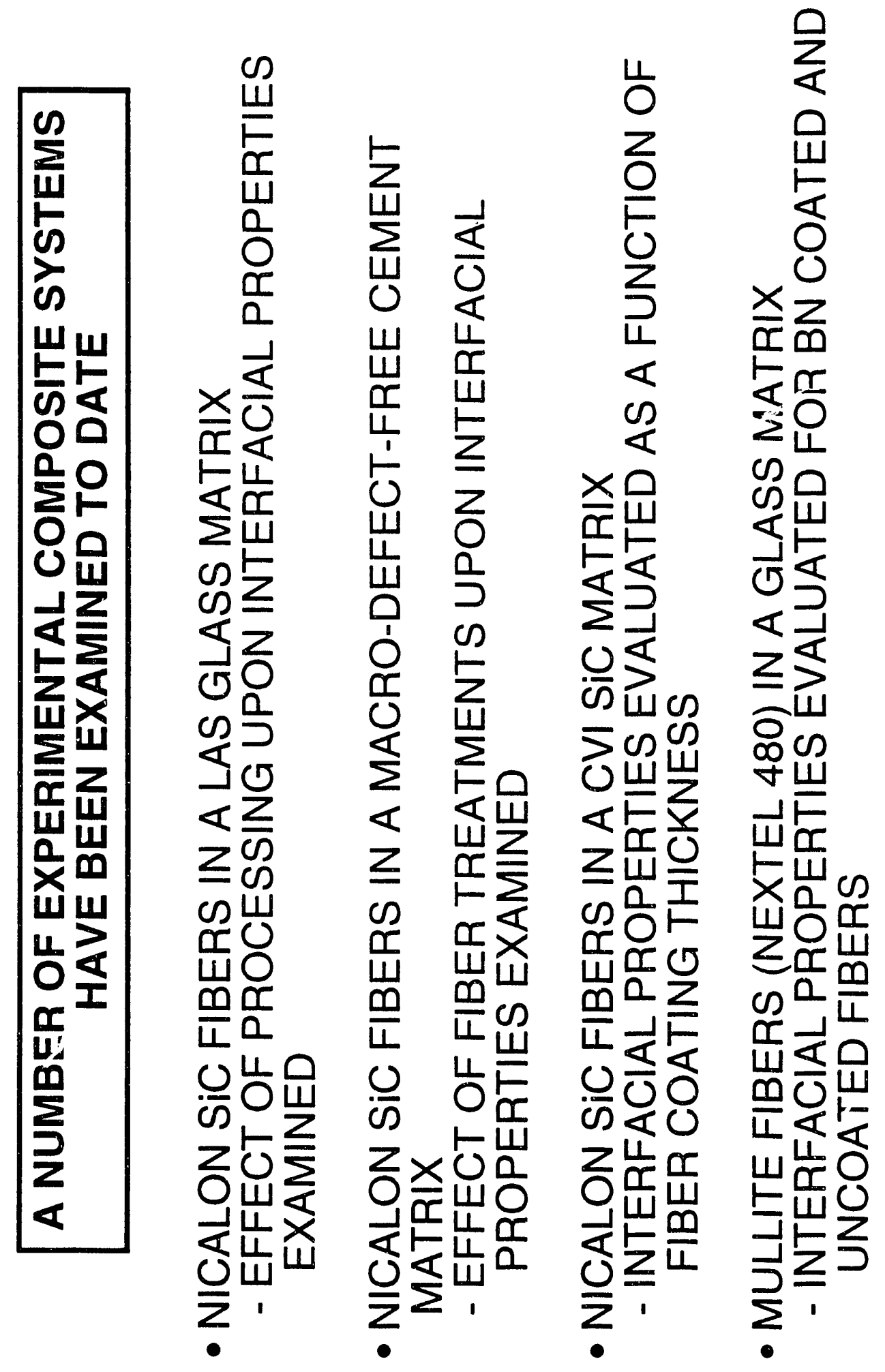




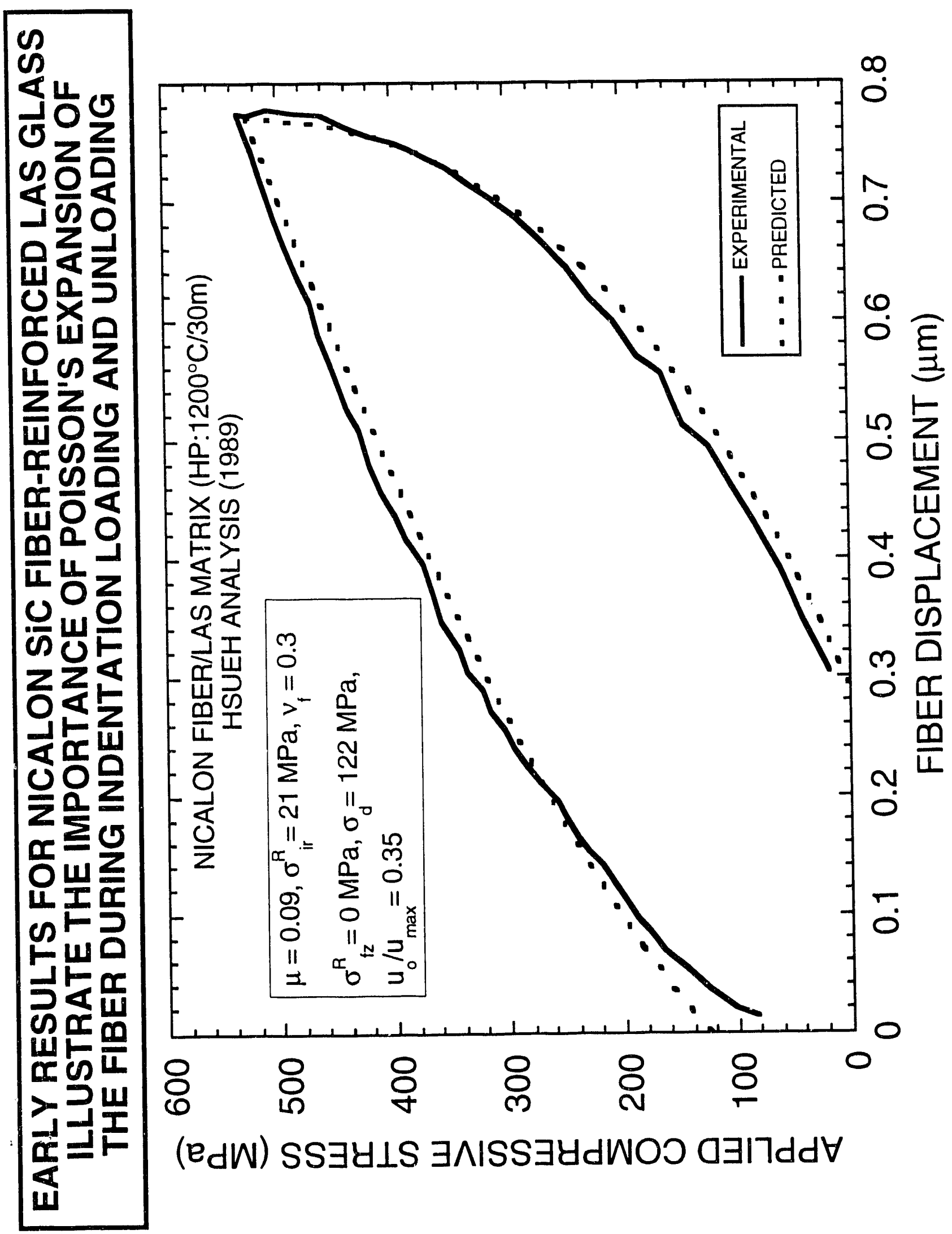




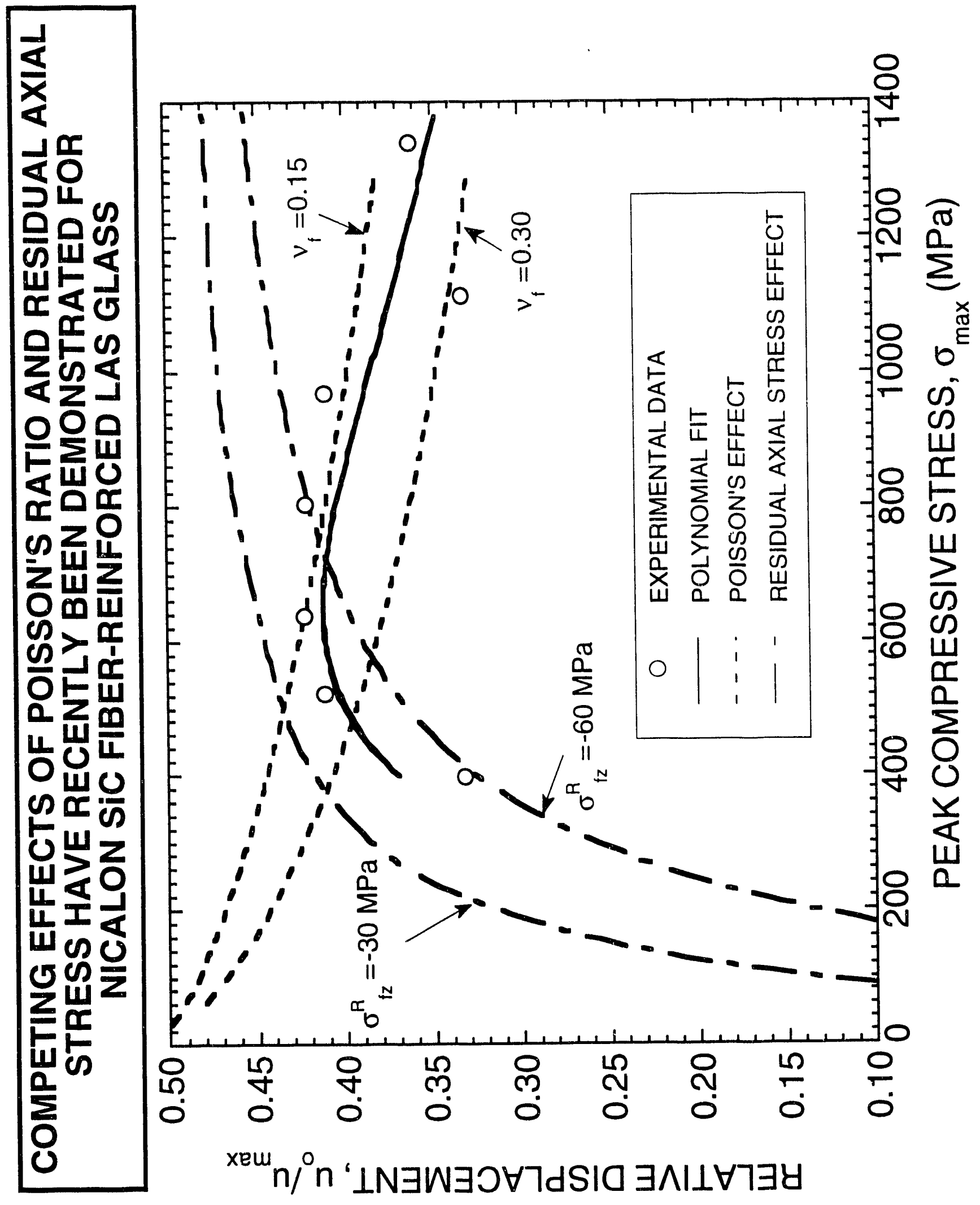




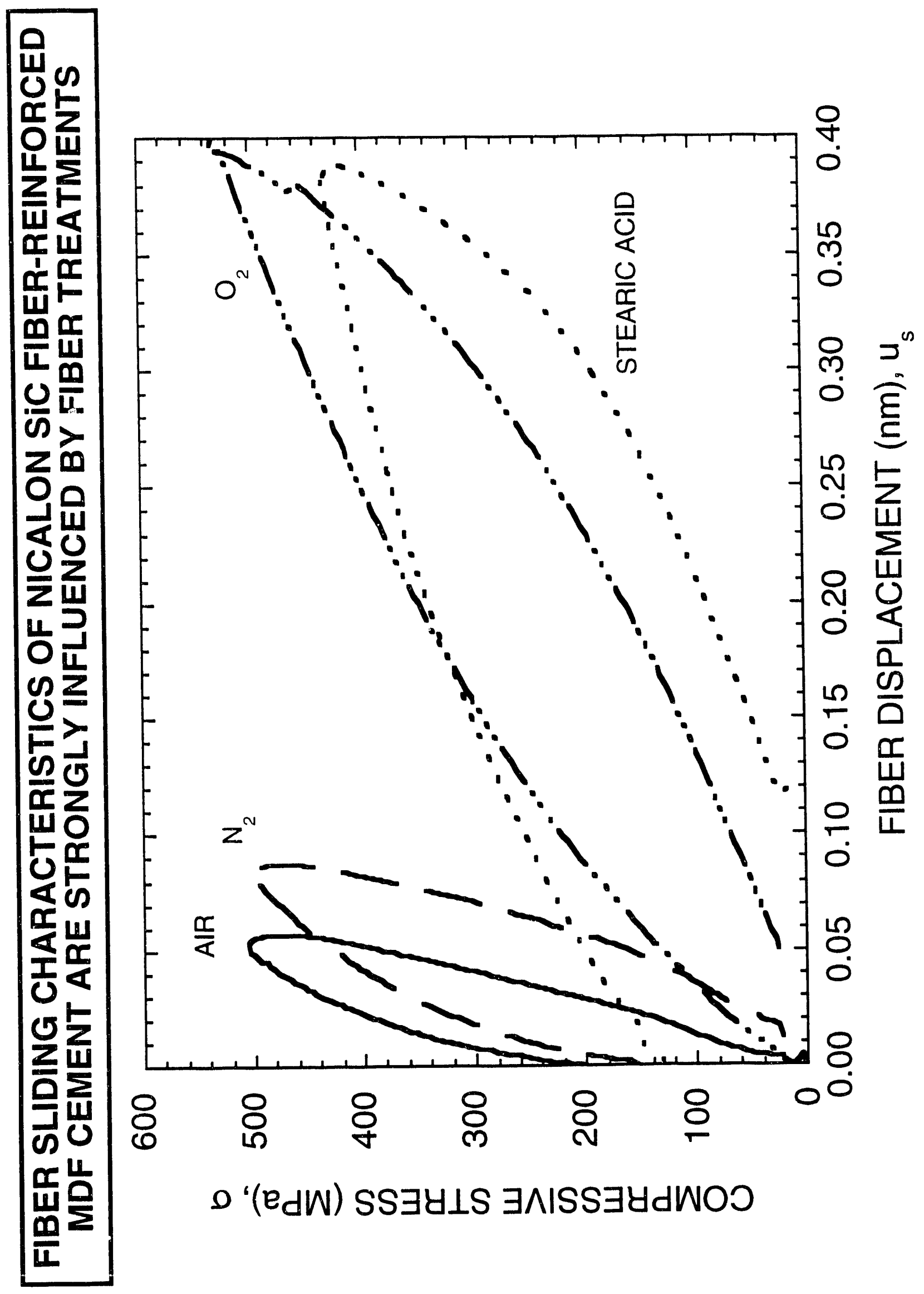




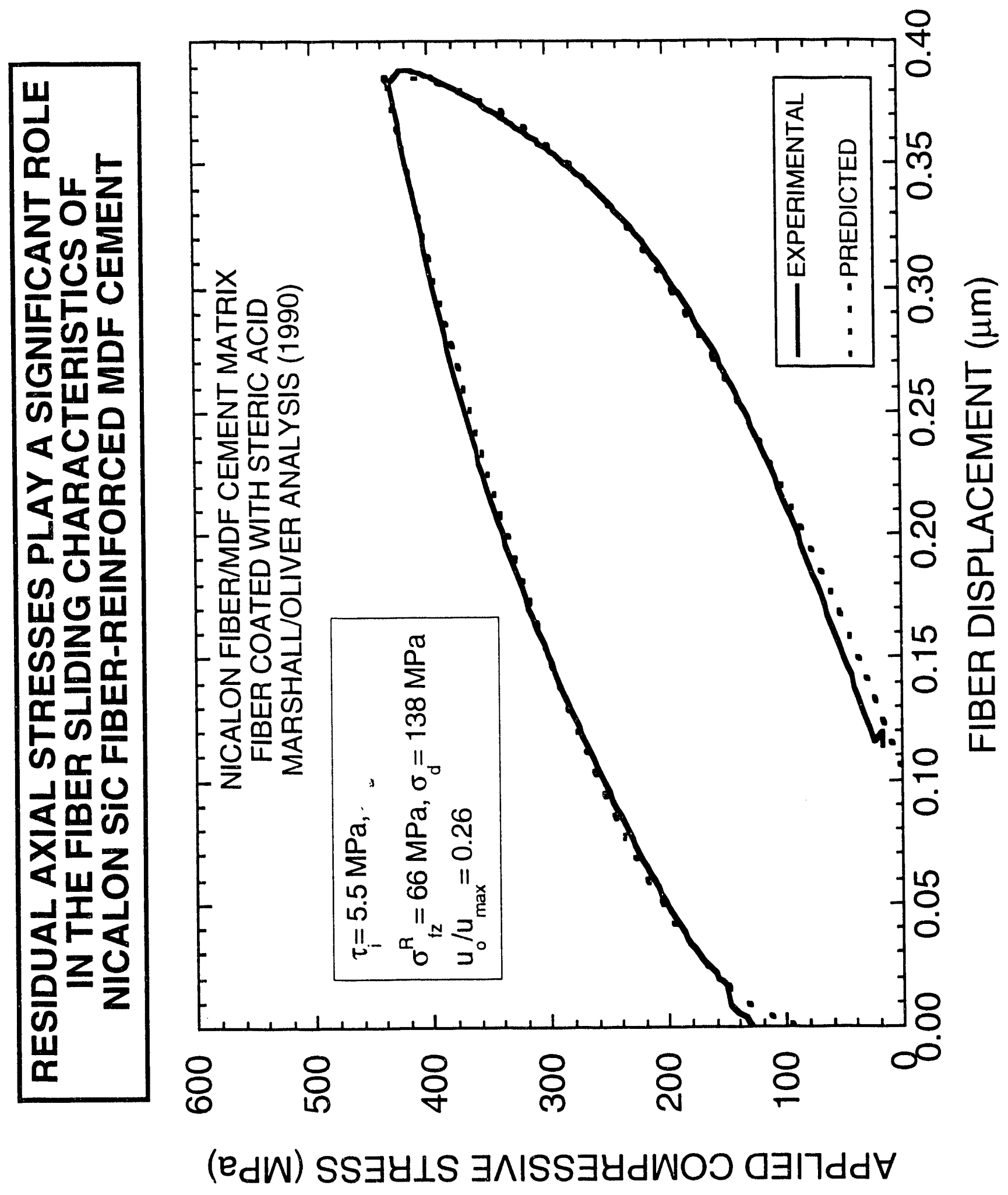




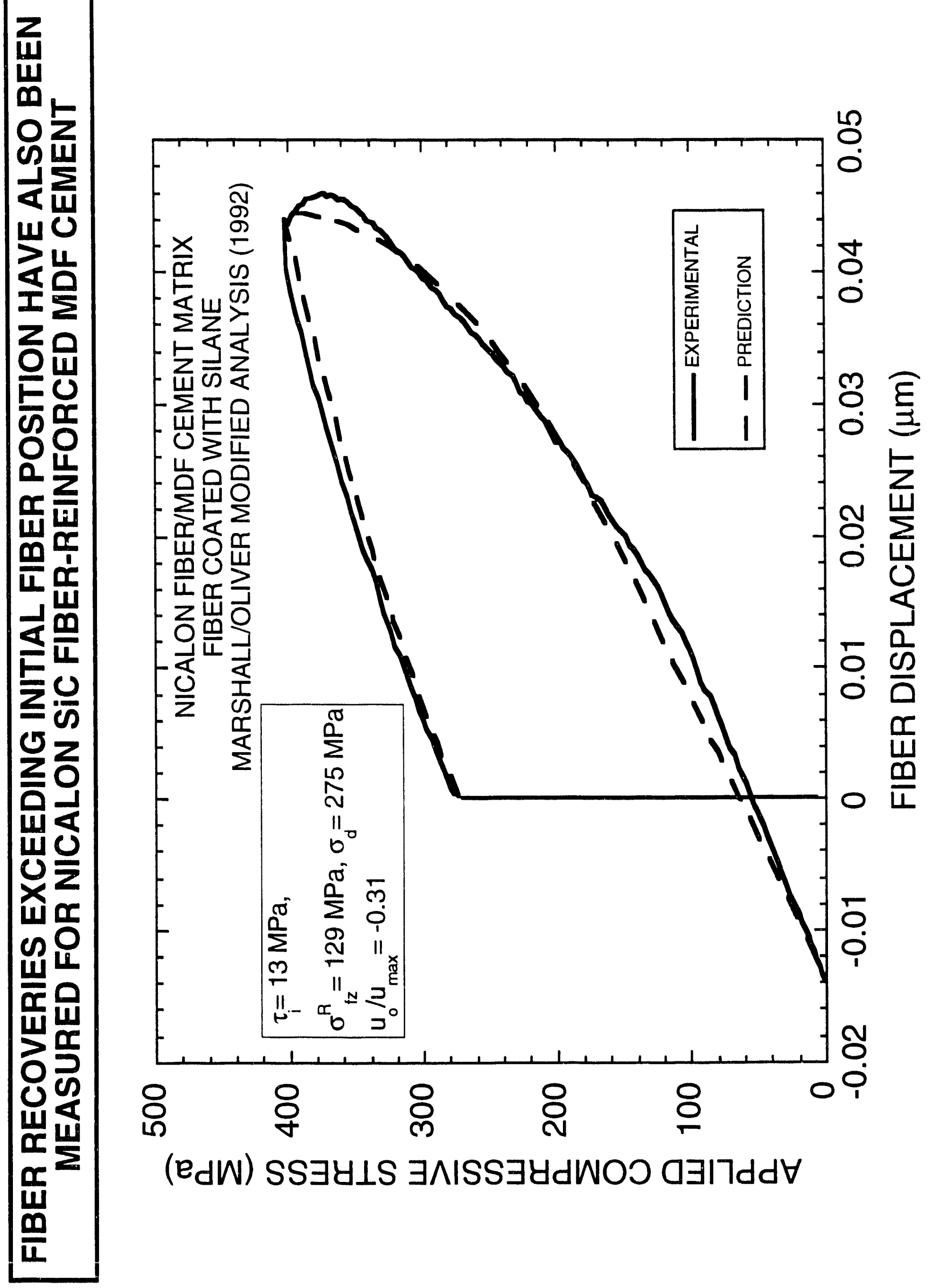




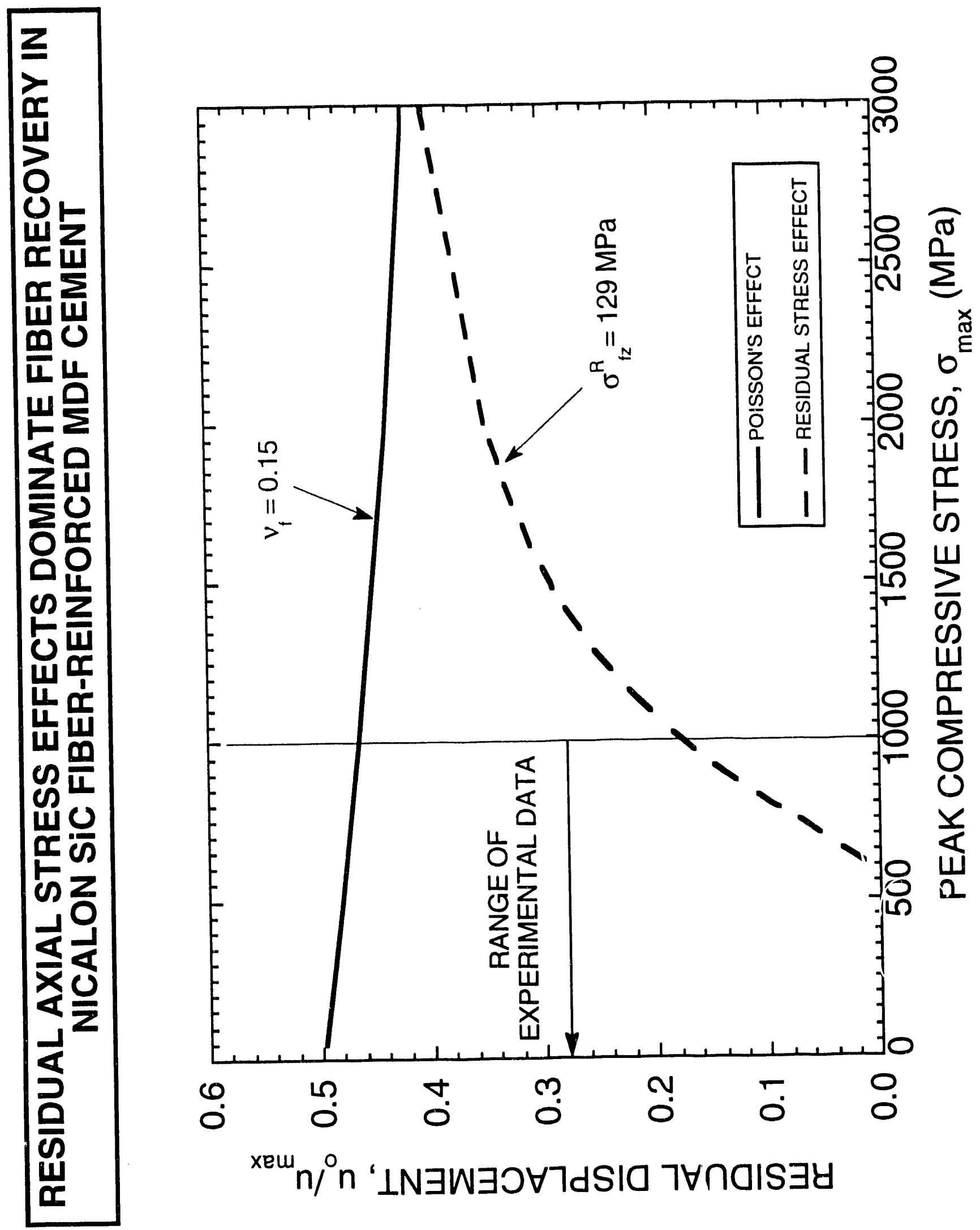




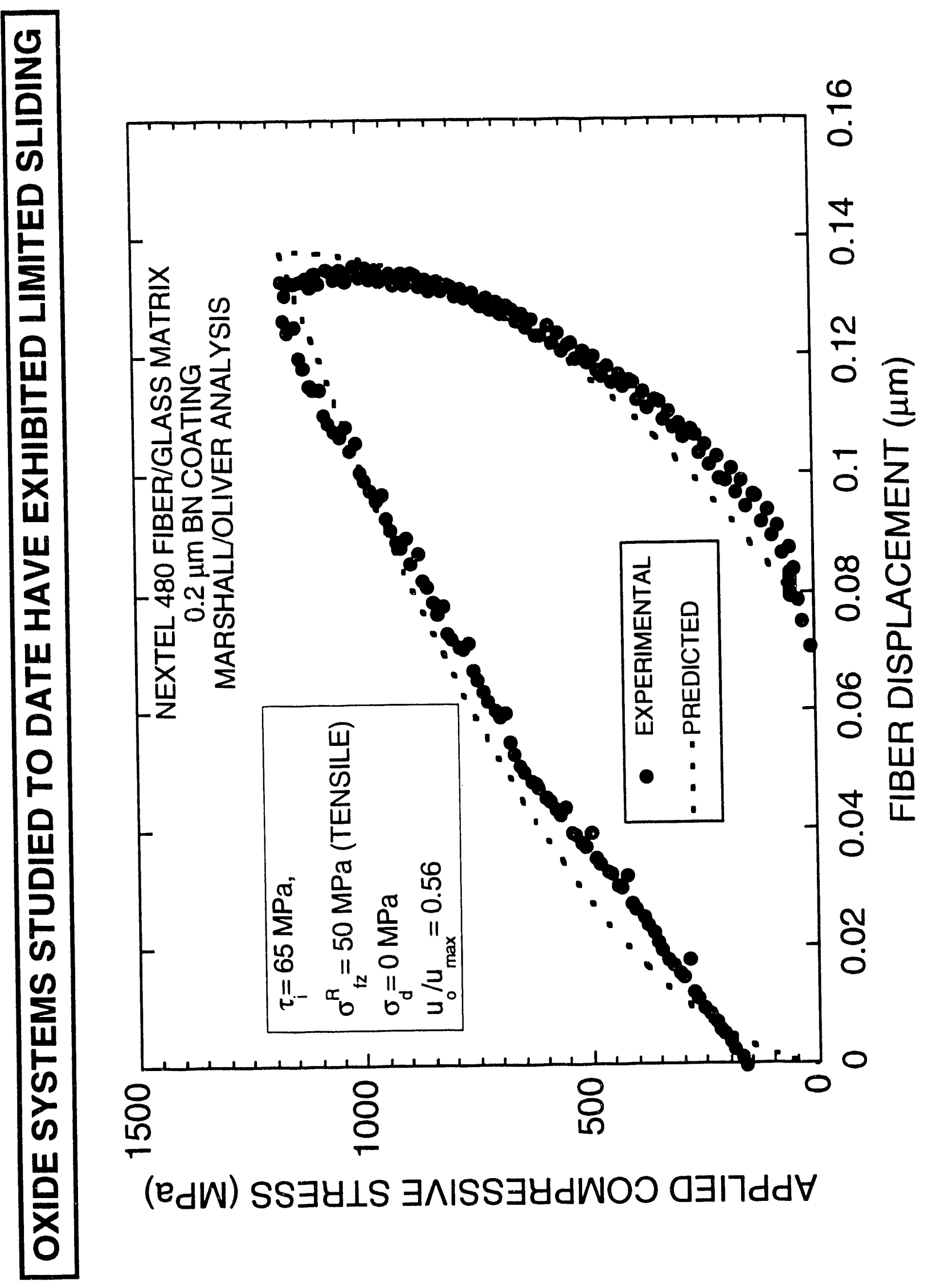




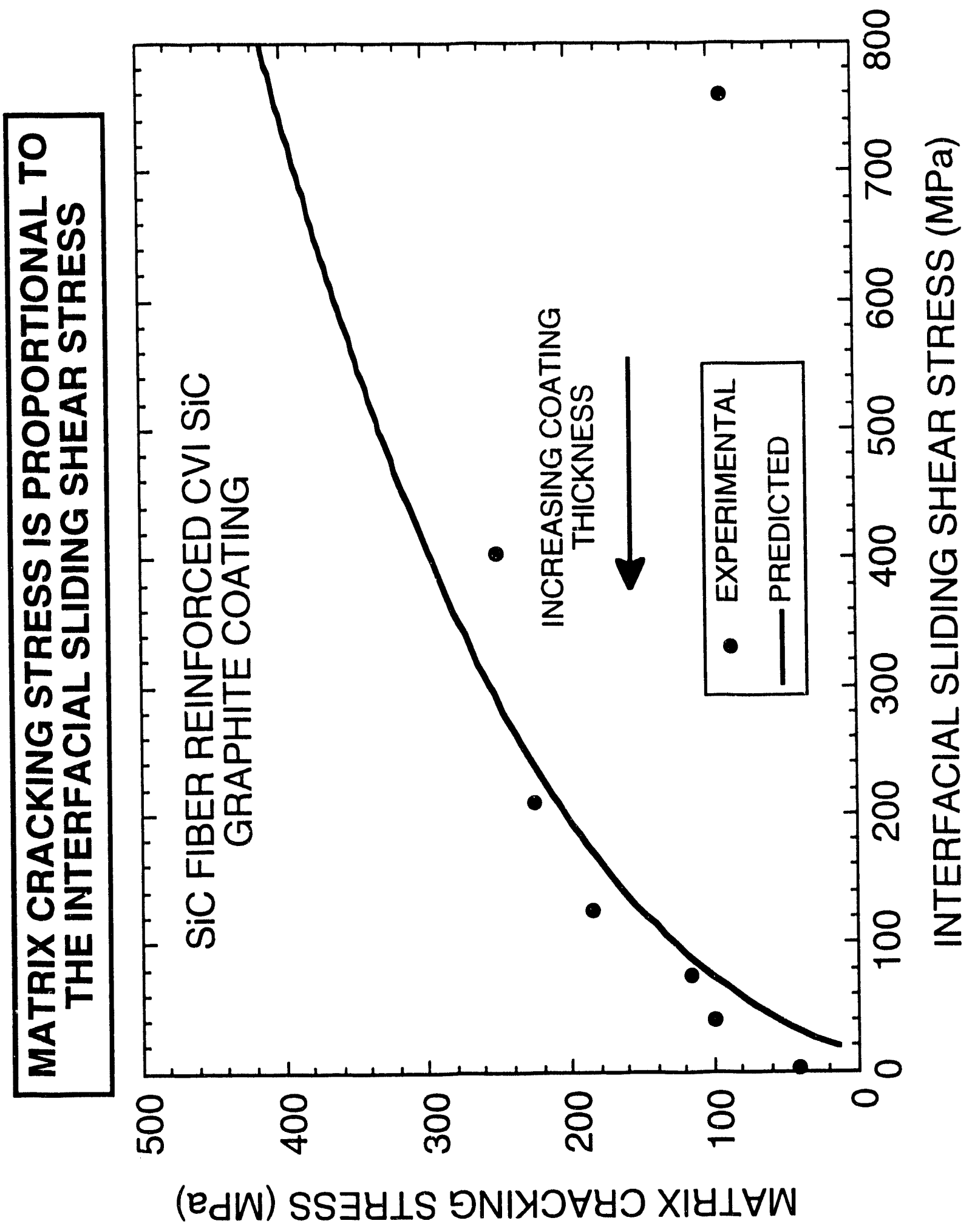




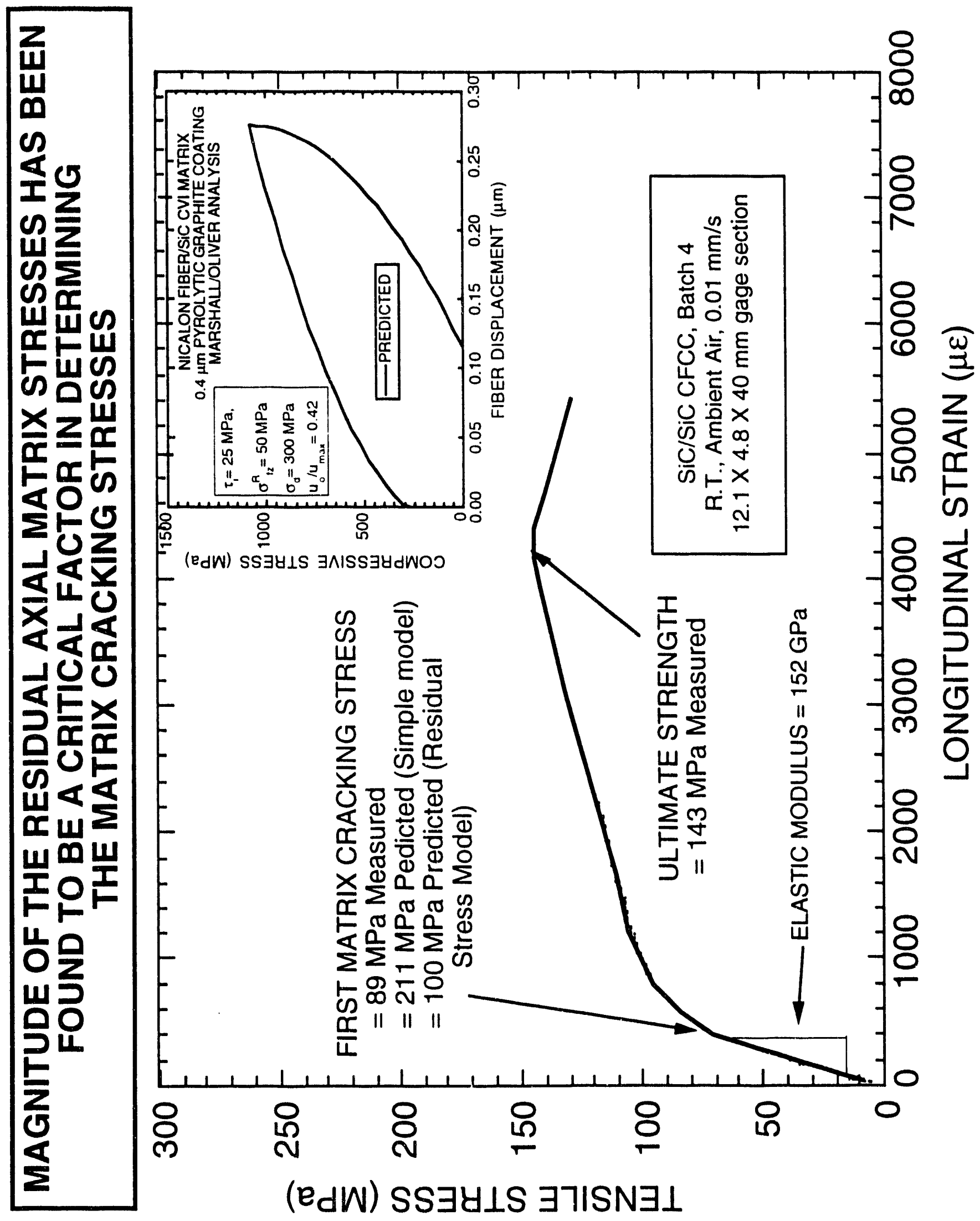




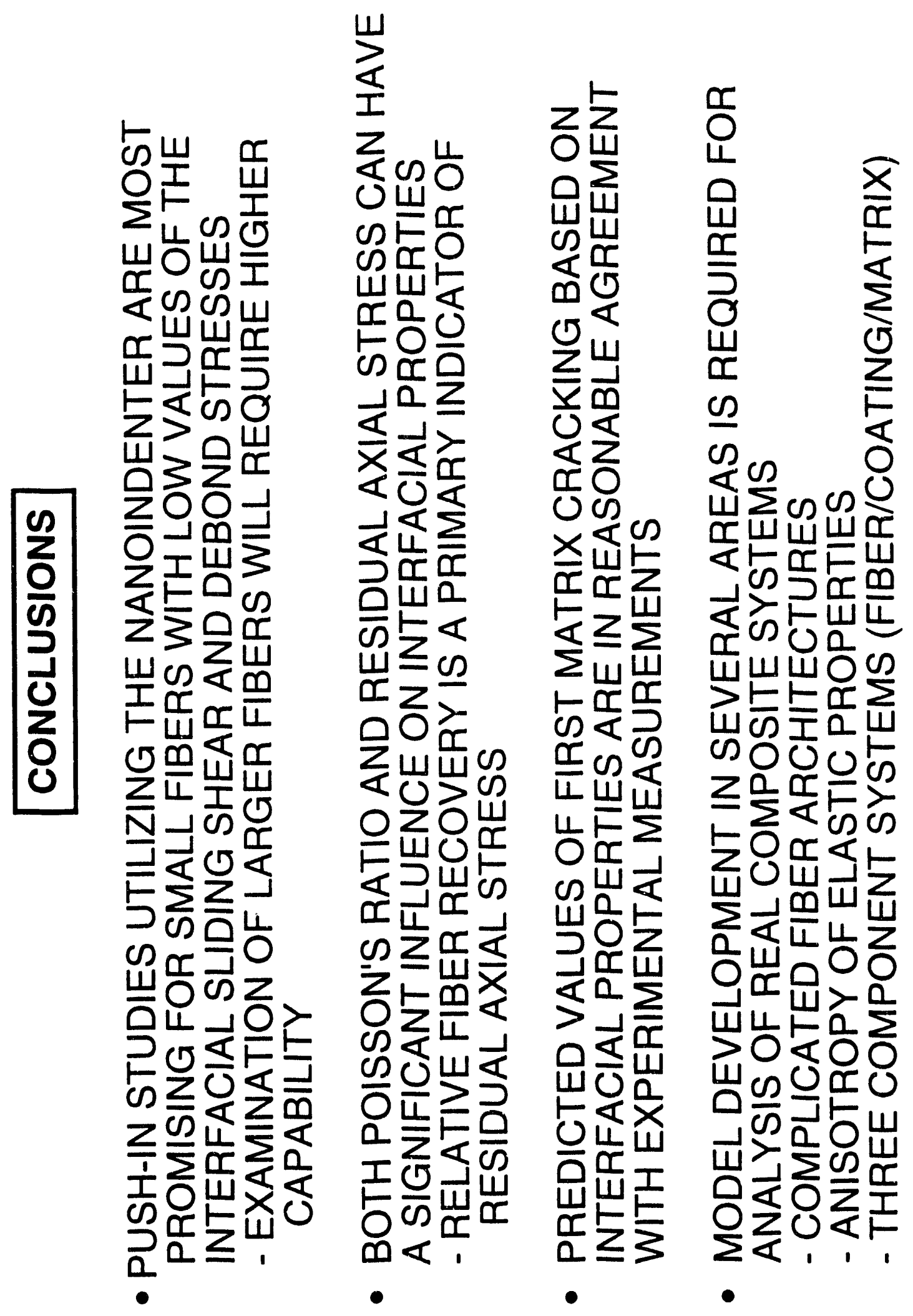




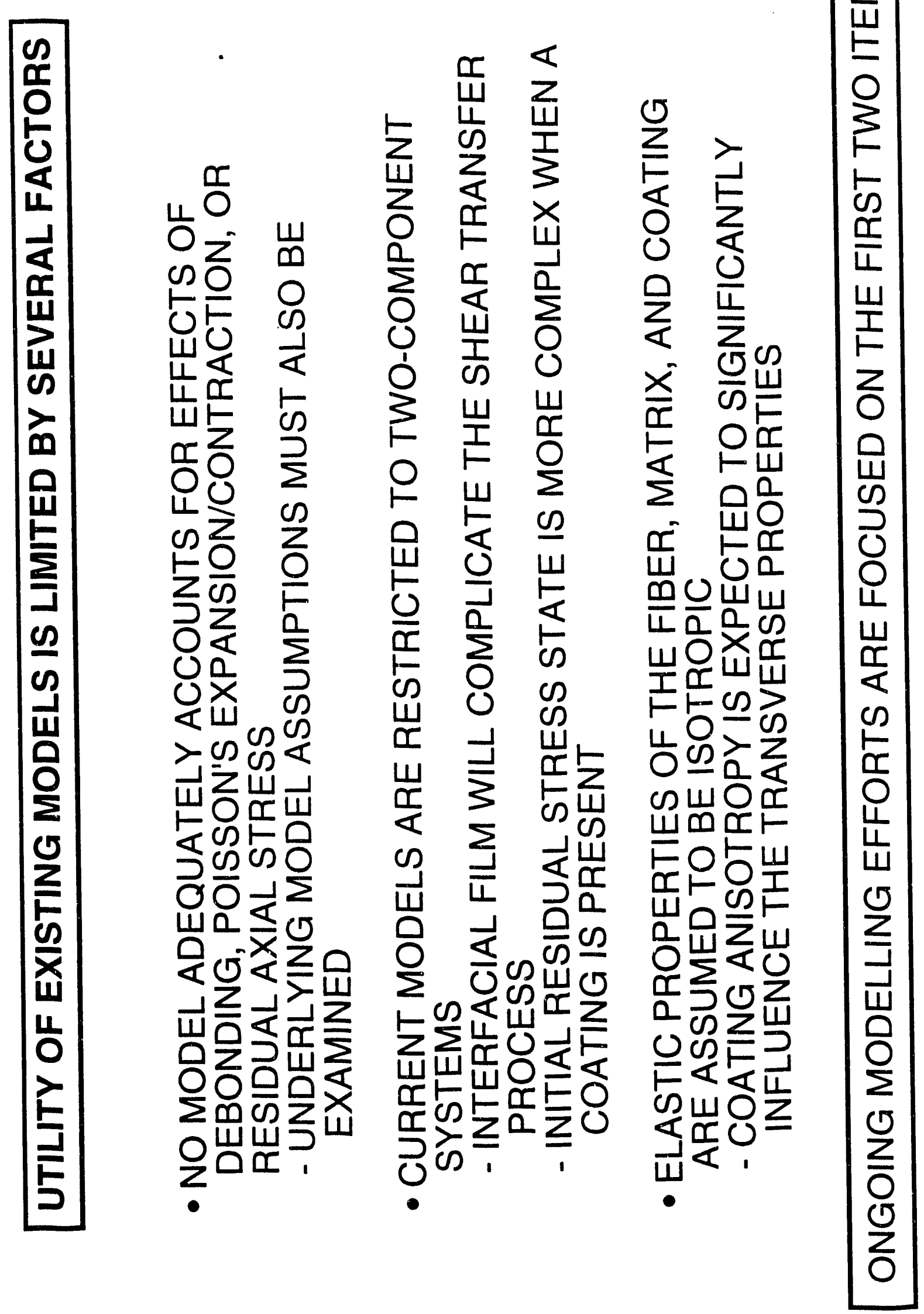



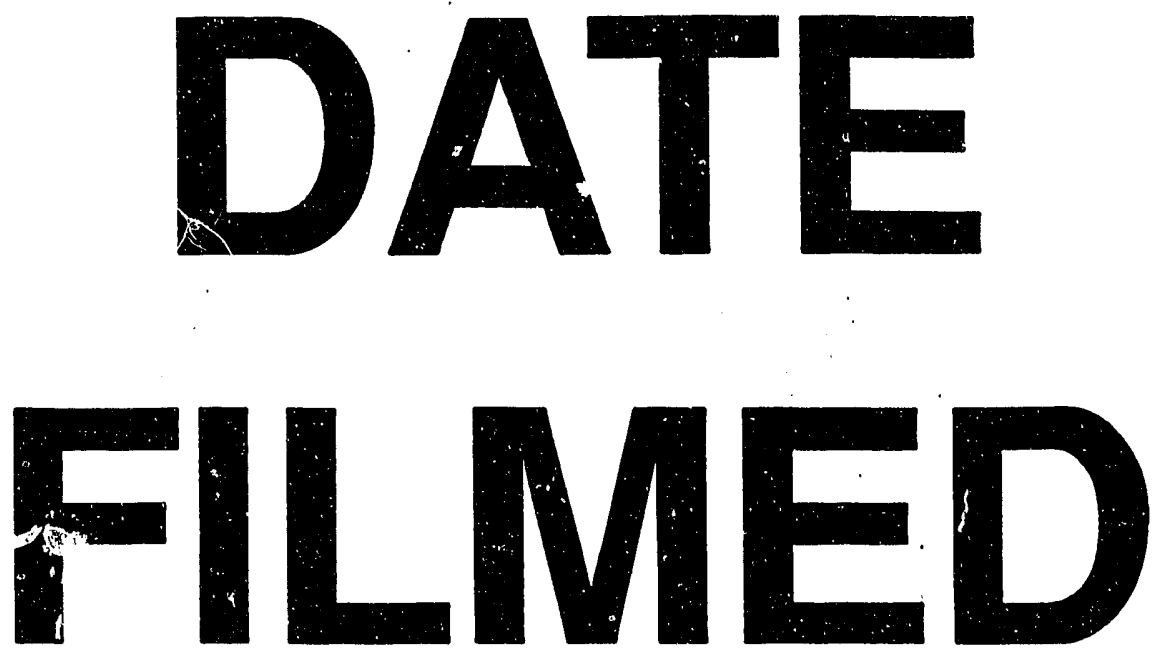

$8 / 17 / 93$
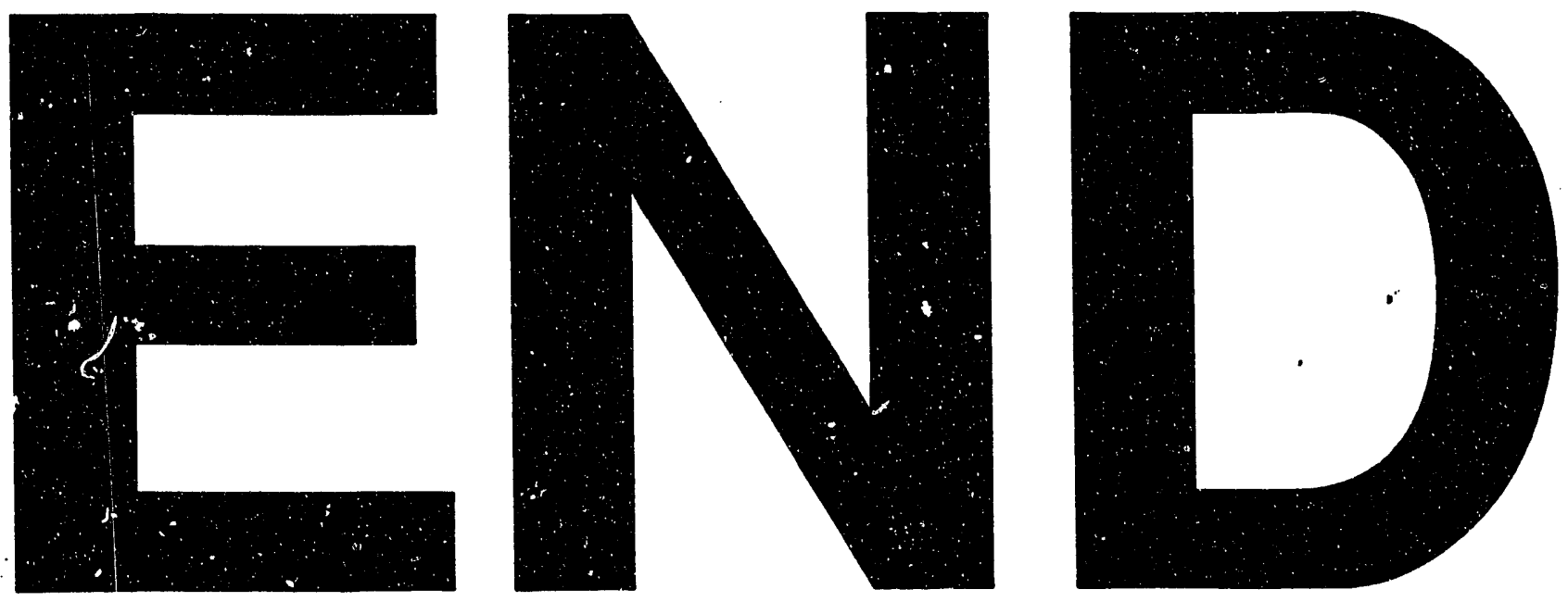

$=$
$=$
$=$
$=$ 
